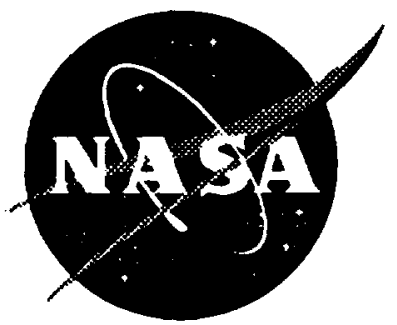

\title{
Modeling and Life Prediction Methodology for Titanium Matrix Composites Subjected to Mission Profiles
}

M. Mirdamadi

Analytical Services and Materials, Inc., Hampton, Virginia

W. S. Johnson

Langley Research Center, Hampton, Virginia

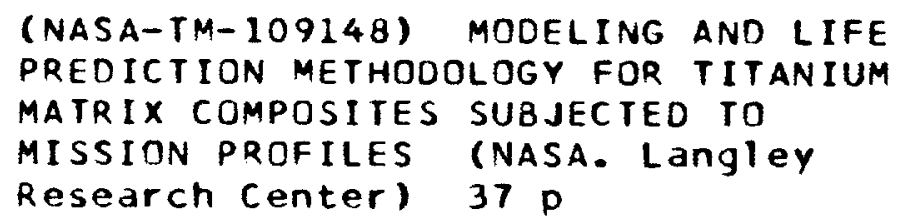

August 1994

National Aeronautics and Space Administration Langley Research Center

Hampton, Virginia 23681-0001 


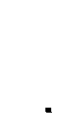




\title{
MODELING AND LIFE PREDICTION METHODOLOGY FOR TITANIUM MATRIX COMPOSITES SUBJECTED TO MISSION PROFILES
}

\author{
M. Mirdamadi ${ }^{1}$, W. S. Johnson ${ }^{2}$
}

\begin{abstract}
Titanium matrix composites (TMC) are being evaluated as structural materials for elevated temperature applications in future generation hypersonic vehicles. In such applications, TMC components are subjected to complex thermomechanical loading profiles at various elevated temperatures. Therefore, thermomechanical fatigue (TMF) testing, using a simulated mission profile, is essential for evaluation and development of life prediction methodologies. The objective of the research presented in this paper was to evaluate the TMF response of the $[0 / 90]_{2 s}$ SCS-6/Timetal-21S ${ }^{\star}$ subjected to a generic hypersonic fight profile and its portions with a temperature ranging from $-130^{\circ} \mathrm{C}$ to $816^{\circ} \mathrm{C}$. It was found that the composite modulus, prior to rapid degradation, had consistent values for all the profiles tested. The accumulated minimum strain was also found to be the same for all the profiles tested. A micromechanics based analysis was used to predict the stress-strain response of the laminate and of the constituents in each ply during thermomechanical loading conditions by using only constituent properties as input. The fiber was modeled as elastic with transverse orthotropic and temperature dependent properties. The matrix was modeled using a thermoviscoplastic constitutive relation. In the analysis, the composite modulus degradation was assumed to result from matrix cracking and was modeled by reducing the matrix modulus. Fatigue lives of the composite subjected to the complex generic hypersonic flight profile were well correlated using the predicted stress in $0^{\circ}$ fibers.
\end{abstract}

KEY WORDS: silicon-carbide fibers, thermomechanical fatigue, residual stresses, viscoplasticity theory, thermal strains

\footnotetext{
${ }^{1}$ Research Scientist, Analytical Services and Materials Inc., Hampton VA 23666.

${ }^{2}$ Senior Research Scientist, NASA Langley Research Center, Hampton VA 23681.

*Timetal-21S is a registered trade mark of Timet.
} 


\section{Introduction}

Silicon-carbide fiber reinforced titanium metal matrix composites (TMC) are being developed for use as structural materials for elevated temperature applications where low weight, high temperature capability, and high stiffness are required. In these applications, TMC components will be subjected to complex flight profiles consisting of a combination of applied thermal and mechanical loads at various elevated temperatures. Due to the large differences in the thermal and mechanical properties of the fiber and the matrix, significant thermal residual stresses develop in the composite. The resulting stress coupled with applied thermal and mechanical loading, can lead to a complex state of stress in these composites. Therefore, thermomechanical fatigue (TMF) testing is critical for evaluation and development of life prediction methodologies. In addition, in order to develop life prediction methodologies for TMC, one must be able to predict the stresses and strains that occur in the constituents of the composite during the complicated TMF loading profiles. Hence, micromechanical based analyses that can account for the viscoplastic behavior of both the fiber and matrix, are helpful in establishing a sound basis for a life prediction methodology.

The objective of this paper is to experimentally evaluate TMF response of the cross-ply SCS-6/Timetal-21S subjected to a generic hypersonic flight profile and its portions. Furthermore, use a micromechanical based analysis to develop an approach to determine the fatigue life of the laminate under TMF mission profile loading conditions.

\section{Background}

A considerable amount of research has been conducted to characterize the fatigue behavior of TMC over the past few years [1-5]. At room temperature, the fatigue response of SCS-6/Ti-15-3 composite, for a variety of lay-ups, was well correlated using the stress range in the $0^{\circ}$ fiber [1] where the $0^{\circ}$ fiber stress was calculated by multiplying the composite stabilized strain range by the fiber modulus [see Fig. 1]. The composites modulus degradation as a result of fatigue cycling were dependent on the composites layup [1]. Analysis of the unidirectional SCS-6/Ti-15-3 composite subjected to TMF loading conditions also showed that the stress in the $0^{\circ}$ fiber controlled the fatigue lives [2]. In [2], the $0^{\circ}$ fiber stress range calculated from a micromechanics analysis was used to compare the in-phase and out-of-phase TMF data reported in $[3,4]$ and shown in Figure 2. The TMF data from [3] had a cycle time of 110 seconds $(0.0091 \mathrm{~Hz})$ and the temperature varied from $300^{\circ} \mathrm{C}$ to $500^{\circ} \mathrm{C}$. The TMF data from [4] had a cycle time of 180 seconds $(0.0056 \mathrm{~Hz})$ and the temperature varied from $93^{\circ} \mathrm{C}$ to $593^{\circ} \mathrm{C}$. As seen in the figure 2, the analysis showed that for a given condition, the fatigue strength of the $0^{\circ}$ fiber was controlled by a combination of temperature, loading frequency, and time at temperature. Furthermore, for a given temperature, loading frequency, and time at temperature, the stress range in the $0^{\circ}$ fiber controlled the fatigue life. 
Additionally, the response of [0/90] $2 s$ SCS-6/Ti-15-3 laminates subjected to several load temperature profiles was investigated [5] and shown in Figure 3. All profiles shown in the figure had the same sustained stress of $420 \mathrm{MPa}$ applied at the sustained temperature of $427^{\circ} \mathrm{C}$. As seen in the figure, the sustained load-sustained temperature test (designated by open circles on Fig. 3) accumulated strain at the fastest rate and resulted in the shortest life. This occurred in spite of the other profiles having cyclic loads and temperatures. The test data also indicated that the total strain to failure decreased with increased time at temperature and is consistent with the previous findings reported in [2]. Therefore, this difference in life may be more affected by duration of the exposure at elevated temperature than type of loading. Furthermore, microscopic examination of the $[0 / 90]_{2 s}$ SCS-6/Ti-15-3 composite subjected to the sustained stress of $420 \mathrm{MPa}$ applied at the sustained temperature of $427^{\circ} \mathrm{C}$ [6] revealed that the strain accumulation was due primarily to internal damage in the form of fiber-matrix debonding and matrix cracking and not deformation associated with conventional creep. It was also observed [6] that the internal damage initiated and grew from the fiber-matrix interface in the $90^{\circ}$ plies and progressed toward the $0^{\circ}$ plies. The final failure of the $0^{\circ}$ fiber occurred just prior to the failure of the composite. These results indicate that in a cross-ply laminate, the damage and failure of the $90^{\circ}$ plies occurs at an early stage, resulting in stress redistribution. However, the final failure of the composite is governed by the stress in the $0^{\circ}$ fibers.

Increased exposure at elevated temperature could also produce more reaction between the fiber and the matrix, lowering the static strength in [7] and fatigue resistance as in [8]. Therefore, the stress (strain) in the $0^{\circ}$ fiber stress plays a major role in fatigue strength of TMCs and could be used as a basis for development of life prediction methodologies.

\section{Material and Test Specimens}

The material used in this study was SCS-6/Timetal-21S which was fabricated into a $[0 / 90]_{2 s}$ laminate by hot isostatic pressing (HIPing) of Ti-15Mo-3Nb-3Al-0.2Si foil between tapes of unidirectional SCS- 6 silicon-carbide fibers having a diameter of 0.14 $\mathrm{mm}$. The fibers were held in place with $\mathrm{Ti}-\mathrm{Nb}$ crossweave wires. An average volume fraction of 0.365 was measured for this laminate.

Rectangular specimens having a length of $152-\mathrm{mm}$, width of $12.7-\mathrm{mm}$ and thickness of $1.69-\mathrm{mm}$, were machined using a diamond wheel saw. Brass tabs $(10-\mathrm{mm}$ by $30-\mathrm{mm}$ by $1-\mathrm{mm}$ ) were placed between the end of the specimen and the grips to avoid specimen failure in the grips. Prior to testing, each specimen was heat treated (aged) at $621^{\circ} \mathrm{C}$ for eight hours in a vacuum to stabilize the matrix material. 


\section{Experimental Procedure}

A TMF test capability, was developed to conduct a series of generic hypersonic flight profile simulations. The detailed experimental procedure is available in [9]. Briefly, the TMF test setup consists of a 100-kN closed-loop servohydraulic test frame equipped with water cooled hydraulic grips. The test frame is equipped with a load profiler which is capable of generating a variety of waveform segments which can then be combined to construct the required load profiles. The test specimen is heated directly using a 5-kW induction generator with three independent adjustable coils such as developed by Ellis and co-workers [10] controlled by a temperature profiler. Similar to the load profiler, the temperature profiler can be programmed to generate a variety of waveform segments which can then be combined to construct the required temperature profiles. Type $K$ thermocouple wires were spot welded onto the specimen's surface for the purposes of monitoring and controlling the temperature. In addition, an infrared camera was used to monitor the temperature distribution along the length of the specimen. A temperature variation of $\pm 10^{\circ} \mathrm{C}$ (indicated by thermocouple) was maintained throughout the entire applied temperature profiles.

A combination of forced gaseous and liquid nitrogen was used in conjunction with the water cooled grips to achieve required cooling rate and low temperature of $-130^{\circ} \mathrm{C}$ in the temperature profile. A liquid nitrogen tank was modified to supply liquid and/or gaseous nitrogen at constant pressure. Flow of gaseous and liquid nitrogen was controlled by the temperature profiler. With the addition of liquid and gaseous nitrogen, the temperature profiler was used to reach and control cryogenic temperatures as low as $-130^{\circ} \mathrm{C}$. Rate of cooling is controlled by the temperature profiler through the simultaneous operation of induction heating system and liquid nitrogen cooling system.

Axial strains were measured on the edge of the specimen using a high temperature, quartz rod water-cooled extensometer with a $25-\mathrm{mm}$ gage length. An eight channel analogdigital PC-based data acquisition system using MATE software [11] was periodically utilized to record and store the test data. The analog/digital data acquisition system was capable of recording load, strain, time, and temperature data at predetermined levels of these variables. In addition, a strip chart recorder was also used to continuously record the load, temperature and strain as a function of time. Failure is defined as separation of the test specimen into two pieces and repeat tests were conducted at each test condition.

\section{Generic Hypersonic Profile}

The generic hypersonic flight profile used in this study is shown in Figure 4. All TMF tests were conducted using this flight profile or its portions as shown in Figure 5. The generic hypersonic flight profile consists of Mission I and Mission II, as noted in Figures 4(a) and 4(5). The entire TMF flight profile (Missions I \& II), shown in Figure 4(a), is applied 24 times followed by the TMF flight profile (Missions I \& II), shown in Figure 4b, once. This sequence is repeated until the separation of the test specimen into two pieces. 
The TMF data is reported in terms of the numbers of missions to failure and note that there are two missions (Missions I \& II) in the entire flight profile shown in Figure 4.

The load profile contains segments of continuous fatigue cycling which is shown as heavier lines in the figure. The mechanical fatigue cycles are applied at a frequency of 1 Hz. The temperature profiles shown in Figures $4 \mathrm{a}$ and $4 \mathrm{~b}$ are the same with a maximum and minimum applied temperature of $816^{\circ} \mathrm{C}$ and $-130^{\circ} \mathrm{C}$, respectively. The heating and cooling rates of the temperature profile are $2.8^{\circ} \mathrm{C} / \mathrm{sec}$ and $1.4^{\circ} \mathrm{C} / \mathrm{sec}$, respectively. The loading profiles in Figures 4(a) and 4(b) have slight differences. In Figure 4(a), the maximum applied stress in the loading profile is $336 \mathrm{MPa}$, while the maximum applied stress in Figure $4(\mathrm{~b})$ is $420 \mathrm{MPa}$. In addition, Figure $4(\mathrm{~b})$ contains the segment of the loading profile designated as $\mathrm{d}-\mathrm{e}-\mathrm{f}$ which is in-phase with the applied temperature.

\section{Analytical Method}

A two dimensional micromechanical model, VISCOPLY, was used to predict the stressstrain response of the composite and of the constituents in each ply during thermomechanical loading conditions by using only constituent properties as input. The VISCOPLY code, developed by Bahei-El-Din, uses the vanishing fiber diameter (VFD) model [12] to calculate the orthotropic properties of a ply. The ply properties are then used in a laminated plate theory [13] to predict the overall laminate response. Both the fiber and the matrix can be described as thermo-viscoplastic materials.

The viscoplastic constitutive model implemented in the VISCOPLY program was developed by Bahei-El-Din, Shah, and Dvorak [14] for high temperature, isothermal and nonisothermal, applications and is based on the viscoplastic theory of Eisenberg and Yen [15]. This constitutive viscoplastic model assumes the existence of an equilibrium stressstrain response which corresponds to the theoretical lower bound of the dynamic response. In addition, this constitutive viscoplastic model assumes that the elastic response is rate-independent and that inelastic rate-dependent deformation takes place if the current stress state is greater than the equilibrium stress. The inelastic strain rate is described using a power law function of overstress [16] which is defined as the difference between the current stress and the equilibrium stress.

Complex combinations of thermal and mechanical loads can be modeled using the VISCOPLY program. Sequential jobs can be run to vary the order and rate of load and temperature. Fiber and matrix average stresses and strains and the overall composite response under thermomechanical loading conditions are calculated.

Fiber-matrix interface failure, in TMC, occurs early under applied load [1] and must be accounted for in the analysis. Previous work [17] on [0/90] ${ }_{2 s}$ SCS-6/Ti-15-3 composite showed that the fiber-matrix interface failure can be simulated by reducing the fiber transverse modulus in the $90^{\circ}$ plies only. Loss of composite stiffness as a result of matrix 
cracking can also be approximated by reducing the modulus of the matrix in the model. However, it should be pointed out that, due to the assumptions made in the VFD model, local micromechanical effects such as the lateral constraint of the matrix due to the presence of the fibers and stress concentrations in the fibers and matrix are not accounted for in the VISCOPLY program. Nevertheless, the VISCOPLY program has been used to predict the global thermomechanical response within $10 \%$ of the experimental results in similar TMC $[2,17,18]$.

\section{Results And Discussion}

In this section, the experimental fatigue and analytical results are presented. First, the experimental fatigue results for a series of tests simulating a generic hypersonic flight profile and its portions will be discussed. Second, analytical results from VISCOPLY will be compared to the TMF data.

\section{Fatigue Lives}

The experimental fatigue data of cross-ply $[0 / 90]_{2 s}$ SCS-6/Timetal-21S subjected to the hypersonic flight profile and portions of the flight profile are shown in Figure 5. Fatigue life data is presented in terms of completed missions to failure where a mission is the completion of an applied flight profile. Two TMF tests were conducted using the entire flight profile (Missions I \& II) as shown in Figure 5(a) and (b) and a temperature range of $-130^{\circ} \mathrm{C}$ to $816^{\circ} \mathrm{C}$. The test specimens had fatigue lives of 250 and 286 missions, respectively. In both cases, the test specimen failed during the load spike at $427^{\circ} \mathrm{C}$. In order to examine the effect of maximum temperature on fatigue life, two additional tests were conducted using the entire mission profile (Missions I \& II) with a temperature range of $21^{\circ} \mathrm{C}$ to $760^{\circ} \mathrm{C}$. In these two tests, the flight time and the load profile was kept as before, but the maximum temperature was lowered to $760^{\circ} \mathrm{C}$ and the minimum temperature was raised to $21^{\circ} \mathrm{C}$ in Mission I. The fatigue lives under this condition were 372 and 394 missions, respectively. As before, the test specimens failed during the spike load at $427^{\circ} \mathrm{C}$. The observed fatigue lives suggest that the fatigue life was considerably increased by reducing the maximum applied temperature from $816^{\circ} \mathrm{C}$ to $760^{\circ} \mathrm{C}$.

The maximum temperature of $816^{\circ} \mathrm{C}$ occurs only during Mission I and was suspected to be a portion of the entire flight profile most detrimental to fatigue life. Therefore, additional TMF tests were conducted using only Mission $I$ as shown in Figure 5(c) and 5(d). Under Mission I, with a temperature range of $-130^{\circ} \mathrm{C}$ to $816^{\circ} \mathrm{C}$, the test specimens had fatigue lives of 192 and 198 missions during the spike load at $427^{\circ} \mathrm{C}$. To examine if the cryogenic temperature had any effect on the fatigue life, two additional tests were conducted using Mission I with the temperature ranging from $21^{\circ} \mathrm{C}$ to $816^{\circ} \mathrm{C}$. The fatigue 
lives were 200 and 186 missions during the spike load at $427^{\circ} \mathrm{C}$. These results indicated that the cryogenic temperature of $-130^{\circ} \mathrm{C}$ to $816^{\circ} \mathrm{C}$ did not produce any noticeable effect on fatigue life over specimens tested from $21^{\circ} \mathrm{C}$ to $816^{\circ} \mathrm{C}$. As compared to the fatigue results from the entire flight profile (Missions I \& II), it was observed that Mission I alone resulted in the failure of the composite.

Since Mission I resulted in fatigue failure, critical portions of Mission I were examined. As indicated in Figure 4b, Mission I contains a load portion (designated as d-e-f) which is in-phase with the applied temperature at the maximum temperature of $816^{\circ} \mathrm{C}$ and occurs once every 25th flight. One TMF test was conducted on this isolated portion of Mission I as shown in Figure 5(e). The results of the TMF test under this loading condition did not cause failure after 300 missions and the test was considered a runout. Recall that the fatigue results obtained using the entire flight profile (Missions I \& II) had an average fatigue life of 268 missions during which the isolated portion (Figure 5(e)) occurred only five times. It is apparent that this portion by itself is not detrimental to the fatigue life, therefore, this portion including a load spike to a maximum applied stress of $420 \mathrm{MPa}$ at $427^{\circ} \mathrm{C}$ was included in the testing profile as shown in Figure 5(f). Two TMF tests were conducted under this loading condition. The test specimens failed at 264 and 259 flights during the spike load at $427^{\circ} \mathrm{C}$. From these results, inclusion of the load spike did not result in a considerable reduction in the fatigue life. Again, comparing these results with those obtained under the Missions I and II, with the average fatigue life of 268 missions, this portion would only occur about five times. Therefore, even though this portion resulted in fatigue failure, it was not considered as a critical portion of Mission I alone. Although, not shown in Figure 5, one TMF test was conducted using Mission II of the flight profile, shown in Figure 4(b) which occurs once every 25 flights. In Mission II, the load profile contains a spike to the maximum applied stress of $420 \mathrm{MPa}$ and $427^{\circ} \mathrm{C}$, and a segment of 720 second hold-time at the applied stress of $286 \mathrm{MPa}$ and $427^{\circ} \mathrm{C}$. The TMF test was conducted under this condition and the test specimen endured 300 flights without failure and was considered a runout.

The fatigue results obtained in this section indicate that the fatigue response is influenced by the applied maximum temperature, applied stress, and time at temperature. Furthermore, these results suggest that the isothermal, simple in-phase and out-of-phase TMF test results may not be extrapolated to describe the TMF flight profile. Therefore, it is essential that the effects of parameters, such as stress, temperature, and time at temperature on fatigue be understood for development of life prediction methodology.

\section{Stress Strain Behavior}

Detailed stress strain responses and modulus histories for all the TMF mission profiles tested will be presented elsewhere. In this section, only the response under the entire hypersonic flight profile (Figures 5(a) and 5(b)) and portion of Mission I (Figure 5(f)) will 
be discussed. The stress-strain response, was periodically recorded and the elastic modulus was calculated over the lives of the test specimens. As shown in Figure 6, the elastic modulus was calculated at room temperature (initial loading), $\mathrm{E}_{\mathrm{i}}$, at $427^{\circ} \mathrm{C}$ during unloading of the load spike, $E_{u n}$, and during unloading of the in-phase portion of the 25 th flight where applicable, $E_{\text {in, }}$ for all TMF tests.

The stress-strain responses of the composite subjected to the entire hypersonic flight profile (Missions I \& II) for the temperature range of $-130^{\circ} \mathrm{C}$ to $816^{\circ} \mathrm{C}$ (flights $1,2,75$, and 120) are shown in Figure 7. Under the entire hypersonic profile (Missions I \& II), the elastic modulus is calculated twice, once during Mission I and once during Mission II. As seen in Figure $7(a)$, during the first flight, the initial room temperature modulus,$E_{i}$, dropped from $172 \mathrm{GPa}$ in Mission I to $158 \mathrm{GPa}$ in Mission II, and is mainly due to fiber/matrix interface failure of the $90^{\circ}$ ply [1]. Once the interface has failed, only minor variations in the modulus were noted between Mission I and Mission II in each flight. As seen in Figure 7(b), the composite stress-strain response stabilized in the second flight. The stress-strain response during the 75th and 120th flights are shown in Figures $7(\mathrm{c})$ and 7 (d). As seen in the figures, the measured modulus, at room temperature and $427^{\circ} \mathrm{C}$, degraded with applied flights.

The total accumulative strain and normalized modulus for the composite subjected to the entire hypersonic flight profile with a temperature range of $-130^{\circ} \mathrm{C}$ to $816^{\circ} \mathrm{C}$ are given in Figures 8(a) and 8(b), respectively. As seen in Figure 8(a), the total minimum and maximum strain gradually increased with applied flights. Comparing with the modulus history, shown in Figure 8(b), after initial drop in the modulus, little change to the modulus is observed until the 75th flight. The initial room temperature modulus dropped by $22.5 \%$ and unloading modulus at $427^{\circ} \mathrm{C}$ dropped by $9 \%$. At that point, the moduli decreased at a faster rate until failure. Prior to failure, the unloading modulus at $427^{\circ} \mathrm{C}$ dropped by $14 \%$. During unloading of the in-phase portion of the 25 th flight, the temperature changes from $816^{\circ} \mathrm{C}$ to $732^{\circ} \mathrm{C}$. In this temperature range, the matrix modulus is very low, subsequently any loss in composite stiffness would be attributable to the fiber breakage. By observing that the unloading modulus of the in-phase portion at the 75th and 100th flight did not change, degradation of initial and unloading modulus at $427^{\circ} \mathrm{C}$ is due mainly to the matrix and the fiber/matrix interface cracking. The initial increase in the minimum strain up the point of stabilization causes an increase in the stress level in the $0^{\circ}$ fibers. This combined with the matrix cracking causes additional load to be transferred to the fiber and ultimately results in failure of the laminate.

Figure 9 shows the stress-strain response of the composite subjected to only the portion of Mission I (flights 1, 2, 200, 259) containing the load spike and in-phase loading with the applied temperature represented by Figure 5(f). As seen in Figure 9, a larger amount of permanent strain is observed in the first flight than the subsequent flights due to the high applied load and temperature. Note that, in this profile mechanical loads were applied at 
elevated temperatures and no initial room temperature modulus $\left(E_{i}\right)$ was measured. Very little change is noticed in the unloading modulus of the composite at the spike load between the first and second flight. However, as seen in Figures 9(c) and 9(d) the unloading modulus at $427^{\circ} \mathrm{C}$ degraded in subsequent applied flights. Comparing with the in-phase unloading modulus $\left(E_{\text {in }}\right)$ shown in Figures $9(a)-9$ (d) did not change considerably with the applied flights. Figures 10(a) and (b) show the variation of the total accumulated strain with flights and the normalized modulus history. The total accumulated strain as shown in Figure 10(a) gradually increased until 200 flights, and a larger maximum strain was observed to accumulate in this case compared to previous case. The unloading modulus at $427^{\circ} \mathrm{C}$ as shown in Figure $10(\mathrm{~b})$, after initial drop, gradually degraded up to 200 flights, about $9 \%$, then degraded more rapidly for the remaining life. The unloading modulus at $427^{\circ} \mathrm{C}$, prior to failure dropped by $14 \%$. The in-phase unloading modulus changed little up to 200 flights then decreased at a faster rate for the remaining life. As was mentioned earlier, during unloading of the in-phase portion of the 25th flight, the temperature changes from $816^{\circ} \mathrm{C}$ to $732^{\circ} \mathrm{C}$. In this temperature range, the matrix modulus is very low. Subsequently any loss in composite stiffness would be attributable to the fiber breakage, since the modulus is fiber-dominated.

Comparisons of total accumulative strains and modulus histories, shown in Figures 8 and 10, indicate a consistent level of total accumulative minimum strain. In addition, comparisons of modulus histories indicated that, prior to rapid modulus degradation, the composite axial modulus had consistent value independent of applied loading histories. Furthermore, prior to the rapid modulus degradation the fiber dominated moduli remain essentially constant suggesting that the initial modulus degradation is due mainly to the initiation and growth of interfacial and matrix damage (cracks) to a stable level. The modulus degradation as result of fatigue cycling is dependent on the composites lay-up [1]. Therefore, the modulus histories presented in this work are limited to the $[0 / 90]_{2} \mathrm{~s}$ SCS-6/Timetal-21S.

\section{Theoretical Prediction of Stress-Strain Response}

The VISCOPLY program was used to predict the stress-strain response of the cross-ply SCS-6/Timetal-21S subjected to the TMF flight profiles. The fiber was modeled as elastic with transverse orthotropic and temperature dependency and the matrix was modeled using a thermoviscoplastic constitutive relation which was described previously in the analytical section. A detailed description of the constituent material properties input for use in VISCOPLY are given in [11]. In [12], a variety of TMF loading profiles of this material system, was evaluated and verified. In all the stress-strain response predictions, the fiber/matrix interface failure was modeled by reducing the transverse modulus of the fiber in the $90^{\circ}$ plies. This was shown to be effective in accurately predicting the stress-strain response under a variety of thermomechanical load profiles $[18,19]$ as shown in Figures 11,12 , and 13 for the entire hypersonic flight profile 
(Missions I \& II) and Figure 14 for the portion of Mission I. For clarity, different symbols have been used for Mission I and Mission II. The letters placed at various locations on the stress-strain response can be referenced back to Figure 4 to find the associated segment on the flight profile. As seen in Figure 11, VISCOPLY reasonably predicted the observed experimental stress-strain response of the first flight. However, a larger permanent strain was observed experimentally (as noted in the figure) than was predicted using VISCOPLY, indicating that there may be local plasticity occurring around the fiber which is not accounted for in the VISCOPLY analysis. The experimental stress-strain response stabilized rather quickly, after two flights. However, VISCOPLY predictions did not stabilize until the fifth flight. The experimental and the VISCOPLY predicted stress-strain response of the fifth flight are shown in Figure 12. In the VISCOPLY analysis, the permanent strain observed experimentally during the fifth flight was matched with the strain at start of the analysis. As shown in the figure, the VISCOPLY reasonably predicted the stabilized flight stress-strain response. The experimental stress-strain response and the VISCOPLY prediction for the 25th flight (using profile shown in Figure 4(b)) is shown in Figure 13. As before, the observed permanent strain as a result of flight cycling was incorporated into the VISCOPLY prediction. As seen in the figure, VISCOPLY accurately predicted the observed experimental results.

The experimental stress-strain response and the VISCOPLY predictions of the first five flights of a portion of Mission I (using the profile shown in Figure 5(f)) are shown in Figure 14. As seen in the figure, the experimental stress-strain response stabilized quickly in the second cycle while the VISCOPLY prediction did not stabilize until the fifth flight. As seen in the figure, the VISCOPLY predictions were in excellent agreement with the experimental stress-strain response ( the prediction took four flights to stabilize while the actual test took two flights).

\section{Life Prediction Methodology}

The VISCOPLY program was used to predict the stress in the $0^{\circ}$ fiber for all the TMF profiles tested previously for the stabilized condition and the condition incorporating matrix damage. For the tests subjected to the entire mission profile shown in Figures 5 (a) and (b) and Mission I profile shown in Figures 5(c) and (d), VISCOPLY predictions of the stress-strain response initially stabilized during the first five flights. Stabilization after the 25th flight (Figure 5(b)) was reexamined and only moderate changes were observed in the VISCOPLY prediction of the $0^{\circ}$ fiber stress. The predicted $0^{\circ}$ fiber stress was then used for analysis of the fatigue data. Using a portion of Mission I profile shown in Figure 5(f), the VISCOPLY prediction of the stress-strain response stabilized after the fifth flight as shown in Figure 14 and the predicted $0^{\circ}$ fiber stress after stabilization was used for the analysis of fatigue data. 
The experimental stress-strain behavior indicated that the composite modulus gradually degraded with flights until failure. As was discussed earlier in the stress strain behavior section, comparisons of modulus histories suggest that the point where the modulus degrades at a faster rate appears to be the onset of $0^{\circ}$ fiber failure. The unloading modulus at $427^{\circ} \mathrm{C}$ at this point (onset of $0^{\circ}$ fiber failure) was found to be $120 \mathrm{GPa}$ in all flight profiles tested. This implies that the damage in the composite, in the form of matrix cracks and fiber/matrix interfacial cracks, has become saturated causing more load to be transferred to the $0^{\circ}$ fibers leading to eventual failure at points of highly localized stress. As was mentioned earlier, the fiber/matrix interface failure was modeled by reducing the fiber transverse modulus of the $90^{\circ}$ plies. To simulate the matrix cracking, the matrix modulus was reduced in the VISCOPLY prediction. Figure 15 shows the VISCOPLY prediction of the composite modulus and stress in the $0^{\circ}$ fiber as a function of percent retention of the matrix modulus at $427^{\circ} \mathrm{C}$ when the composite is loaded to $420 \mathrm{MPa}$. As seen in the figure, reducing the matrix modulus lowers the composite modulus, resulting in higher stress in the $0^{0}$ fibers. For all the profiles tested, the unloading modulus at $427^{\circ} \mathrm{C}$ was found to be about $120 \mathrm{GPa}$ at the point where the modulus begins to decrease rapidly. The composite modulus of $120 \mathrm{GPa}$ was used in Figure 15 to determine the proper reduction in the matrix modulus and was used in the VISCOPLY program to predict the stress-strain response. Figure 16 shows the stress-strain response of the composite after 200 flights where the unloading modulus was measured to be $120 \mathrm{GPa}$. The VISCOPLY prediction simulating matrix cracking is also shown in the figure. In the prediction, the matrix modulus was reduced by the same magnitude at all temperatures as was determined for $427^{\circ} \mathrm{C}$ and the resulting prediction agreed well with the observed experimental results as seen in Figure 16. Figure 17 shows the predicted $0^{\circ}$ fiber stress as a function of time for the first five flights, stabilization, and subsequent prediction simulating matrix cracking. As seen in the figure, the maximum fiber stress increases with each subsequent flight. The increase in fiber stress is due to stress relaxation in the matrix followed by simulated matrix cracking and subsequent load transferal to the fibers as predicted by the VISCOPLY program.

The fatigue data were analyzed using the stress in the $0^{\circ}$ fiber as described above. Three criterion were considered for analysis of fatigue data, maximum stress $\left(\sigma_{\max }\right)$, stress range $(\Delta \sigma)$ and Smith-Watson-Topper parameter [21]. While maximum stress and stress range traditionally are used to describe fatigue response, the Smith-Watson-Topper (SWT) effective strain (stress) takes into account the stress ratio effect. The SWT effective strain $\left(\Delta \varepsilon_{\text {eff }}\right)$ is given by:

$$
\Delta \varepsilon_{\text {eff }}=\left(\frac{\varepsilon_{\max } \Delta \varepsilon}{2}\right)^{1 / 2}
$$


In Eq. (1), $\varepsilon_{\max }$ and $\Delta \varepsilon$ are the maximum strain and strain range respectively. Assuming elastic fiber response, the SWT parameter can be written in terms of stress as:

$$
\Delta \sigma_{\text {eff }}=\left(\frac{\sigma_{\text {mex }} \Delta \sigma}{2}\right)^{1 / 2}
$$

The fatigue data based on the predicted $0^{\circ}$ fiber stress as a function of time to failure is shown in the Figures 18-20. The time to failure was calculated by multiplying the duration of mission time by the number of missions to failure. The stabilized predictions and predictions including matrix damage are included in Figure 18. For clarity, Figures 19 and 20 include predictions simulating matrix damage. As seen in the figures, the fatigue data are well correlated based on the predicted stress in the $0^{\circ}$ fiber. The analysis suggests that the longer exposure at elevated temperature lowered the fatigue strength of the $0^{\circ}$ fiber. With the limited stress range and maximum in this analysis, the SWT parameter appears to collapse the TMF data into a narrower band.

\section{Summary}

Cross-ply [0/90] $2 \mathrm{~s}$ SCS-6/Timetal-21S composite was subjected to a generic hypersonic

flight profile and its portions with a temperature ranging from $-130^{\circ} \mathrm{C}$ to $816^{\circ} \mathrm{C}$, and the TMF fatigue lives were determined. The composite modulus degraded gradually with applied flights and prior to failure the degradation accelerated. It was also found that the composite modulus prior to the rapid degradation, was consistent in of the flight profiles tested. The accumulative minimum strain was shown to reach a consistent level for all of the flight profiles tested. Stress-strain response of the composite of the first flight and the stabilized flight was well predicted using the VISCOPLY program. The loss of modulus was assumed to be a result of matrix cracking and was modeled in the VISCOPLY program by reducing the matrix modulus. The VISCOPLY program was used with the reduced matrix moduli to predict the composite's consistent stresses in the damage state. Fatigue lives of the composite subjected to the generic hypersonic flight profile were well correlated using the predicted stress in $0^{\circ}$ fibers. This approach can be used to predict fatigue lives for other combinations of TMF loading conditions. 


\section{REFERENCES}

[1] Johnson, W. S., Lubowinski, S. L., and Highsmith, A. L., "Mechanical Characterization of Unnotched $\mathrm{SCS}_{6} / \mathrm{Ti}-15-3$ Metal Matrix Composites at Room Temperature," Thermal and Mechanical Behavior of Metal Matrix and Ceramic Matrix Composites, ASTM STP 1080, J. M. Kennedy, H. H. Moeller, and W. S. Johnson Eds., American Society for Testing and Materials, Philadelphia, 1990, pp. 193-218.

[2] Mirdamadi, M., Johnson, W. S., Bahei-El-Din, Y. A., and Castelli, M. G., "Analysis of Thermomechanical Fatigue of Unidirectional Titanium Metal Matrix Composite," Composite Materials: Fatigue and Fracture, Fourth Volume, ASTM STP 1156, W. W. Stinchcomb and N. E. Ashbaugh Eds., American Society for Testing and Materials, Philadelphia, 1993, pp. 591-607.

[3] Castelli, M. G., Bartolotta P. A., and Ellis, J. R., "Thermomechanical Fatigue Testing of High Temperature Composites: Thermomechanical Fatigue Behavior of SiC (SCS6)/Ti-15-3, " Composite Materials: Testing and Design (Tenth Volume), ASTM STP 1120, Glen C. Grims, ed., American Society for Testing and Materials, Philadelphia, (1991), 70-86.

[4] Gabb, T. P., Gayda, J., and MacKay, R. A. "Isothermal and Nonisothermal Fatigue Behavior of a Metal Matrix Composite," Journal of Composite Materials, 24 (1990), 667-686.

[5] Mirdamadi, M., and Johnson, W. S., "Fatigue of [0/90] $]_{2 s}$ SCS-6/Ti-15-3 Composite Under Generic Hypersonic Vehicle Flight Simulation, "FATIGUE 93, Volume II, Bailon and Dickson, Eds., Chameleon Press, London, pp. 951-956, 1993.

[6] Mirdamadi, M., Bakuckas Jr, J. G. and. Johnson, W. S., "Mechanisms of Strain Accumulation in Titanium Matrix Composites at Elevated Temperatures, "Mechanics of Composite Materials-Nonlinear Effects: AMD Vol. 159, 1993, ASME, pp. 245252

[7] Jeng, S. M., Yang, C. J., Alassoeur, P., and Yang, J. M., "Deformation and Fracture Mechanisms of Fiber-Reinforced Titanium Alloy Matrix Composites, " Proceedings, Eighth International Conference on Composite Materials (ICCM/8), S. W. Tasi and G. S. Springer, Eds., Society for the Advancement of Material and Process Engineering (SAMPE), Covina, CA, 1991, pp. 25-C-1, 25-C-12.

[8] Naik, R. A., Johnson, W. S, and Pollock, W. D., "Effect of High Temperature Cycle on the mechanical Properties of Silicon Carbide/Titanium Metal Matrix Composites, " Proceedings of the ASC on High Temperature Composites, Technomics, Lancaster, PA, 1989, pp. 94-103. 
[9] Mirdamadi, M. , and Johnson, W. S., "Experimental Techniques for Hypersonic Flight Simulation Testing, "Proceedings of the Society of Experimental Mechanics Conference, June 6-8, 1994, pp. 679-684.

[10] Ellis, J. R. and Bartolotta P. A., "Adjustable Work Coil Fixture for Facilitating the Use of Induction Heating in Mechanical Testing," NASA TM-102461, NASA Lewis Research Center, June 1989.

[11] Hartman, G. A. and Ashbaugh, N. E., "A Fracture Mechanics Test Automation System for a Basic Research Laboratory, "Applications of Automation Technology to Fatigue and Fracture Testing, ASTM STP 1092, A. A. Braun, N. E. Ashbaugh, and F. M. Smith, Eds., American Society for Testing and Materials, Philadelphia, pp. 95-110, 1990.

[12] Dvorak, G. J. and Bahei-El-Din, Y. A., "Plasticity Analysis of Fibrous Composite, "Journal of Applied Mechanics, Vol. 49, 1982, pp. 237-335.

[13] Bahei-El-Din, Y. A., "Plasticity Analysis of Fibrous Composite Laminates Under Thermomechanical Loads," Thermal and Mechanical Behavior of Ceramic and Metal Composites, ASTM STP 1080, J. M. Kennedy, N. H. Moeller, and W. S. Johnson, eds., American Society for Testing and Materials, Philadelphia 1990, pp. 20-39.

[14] Bahei-El-Din, Y. A., Shah, R. S., and Dvorak, G. J., "Numerical Analysis of the Rate-Dependent Behavior of High Temperature Fibrous Composites" AMD, Vol. 118: Mechanics of Composites at Elevated temperatures, S. N. Singhal, W. F. Jones, C. T. Herakovich, and T. Cruse, Eds., 1991, pp. 67-78.

[15] Eisenberg, M. A. and Yen, C. F., "A Theory of Multiaxial Anisotropic Viscoplasticity," ASME Journal of Applied Mechanics, Vol. 48, 1981, pp. 276-284.

[16] Malvern, L. E., "The Propagation of Longitudinal Waves of Plastic Deformation in a Bar of Material Exhibiting a Strain-Rate Effect," ASME Journal of Applied Mechanics, Vol. 18, 1951, pp. 203-208.

[17] Johnson, W. S., Mirdamadi, M., and Bahei-El-Din, Y. A., "Stress-Strain Analysis of a [0/90]2s Titanium Matrix Laminate Subjected to a Generic Hypersonic Flight Profile, " NASA Journal of Composites Technology \& Research, JCTRER, Vol. 15, No. 4, Winter 1993, pp. 297-303.

[18] Mirdamadi, M. and Johnson, W. S., "Prediction of Stress-Strain Response of SCS6/Timetal-21S Subjected to the Hypersonic Flight Profile," NASA TM 109026, NASA Langley Research Center, February, 1994 
[19] Smith, K. N., Watson, R., and Topper, T. H., "A Stress-Strain Function for the Fatigue of Metals, " Journal of Materials, Vol. 5, No. 4, 1970, pp. 767-778. 

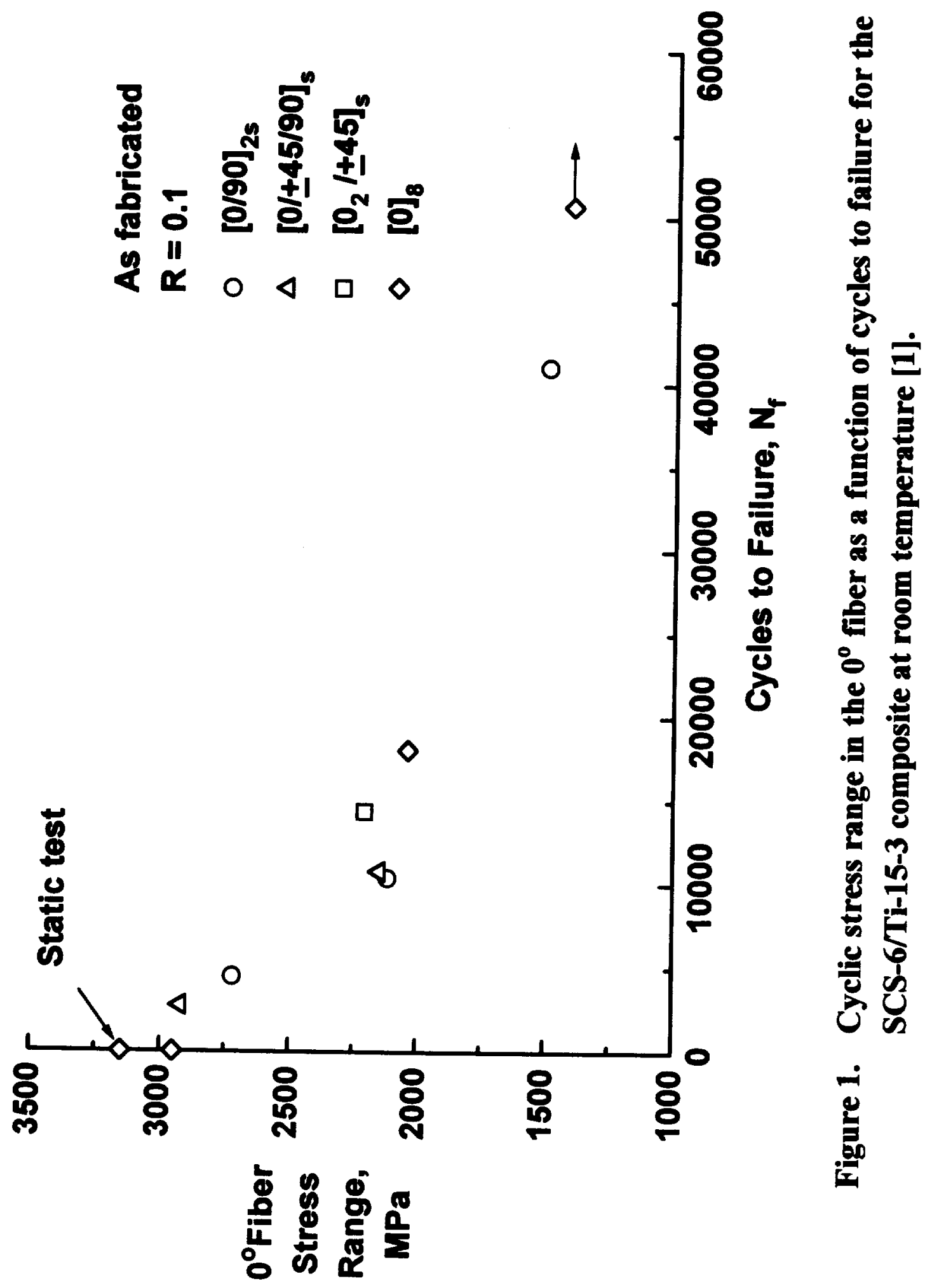


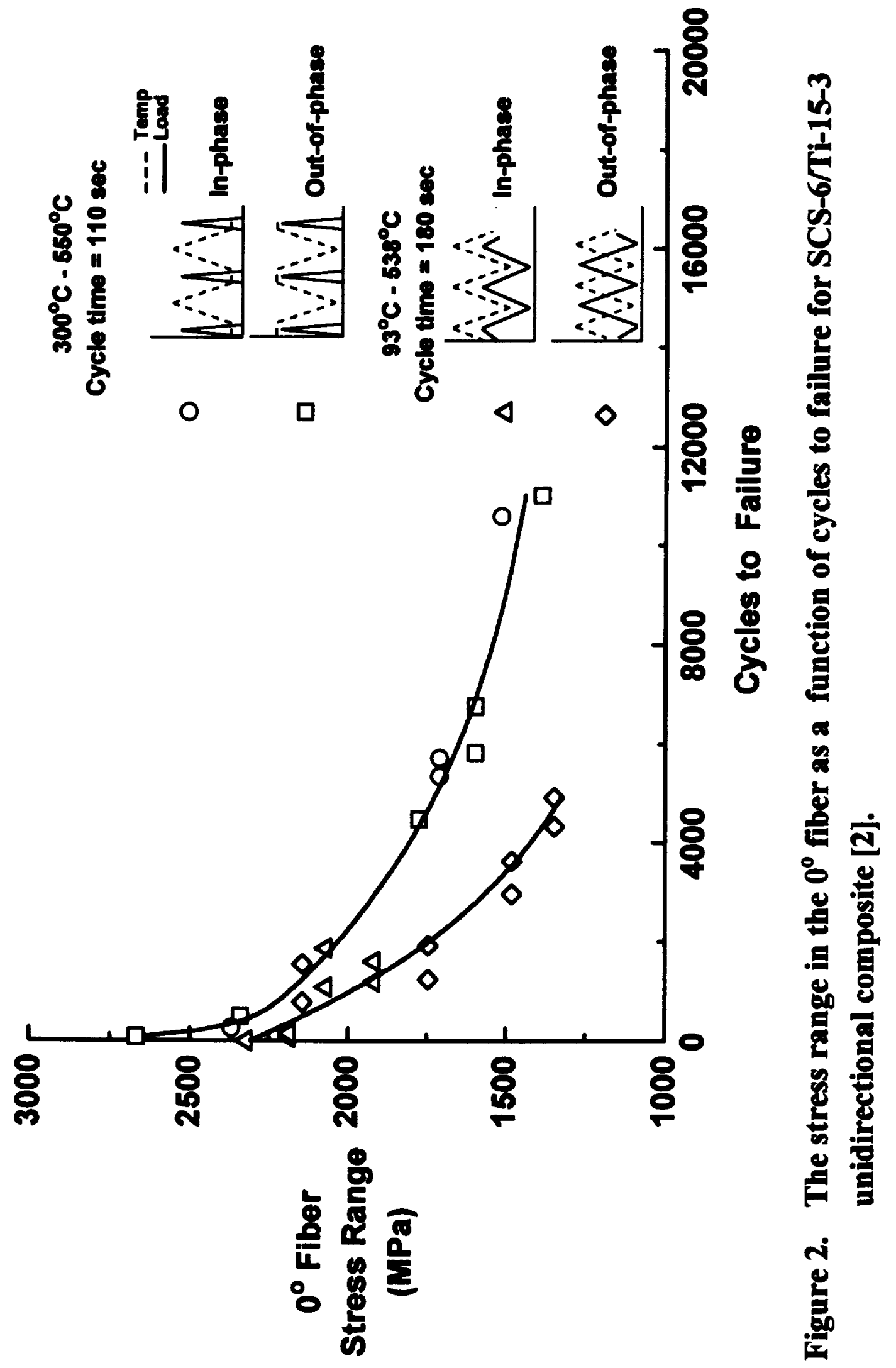



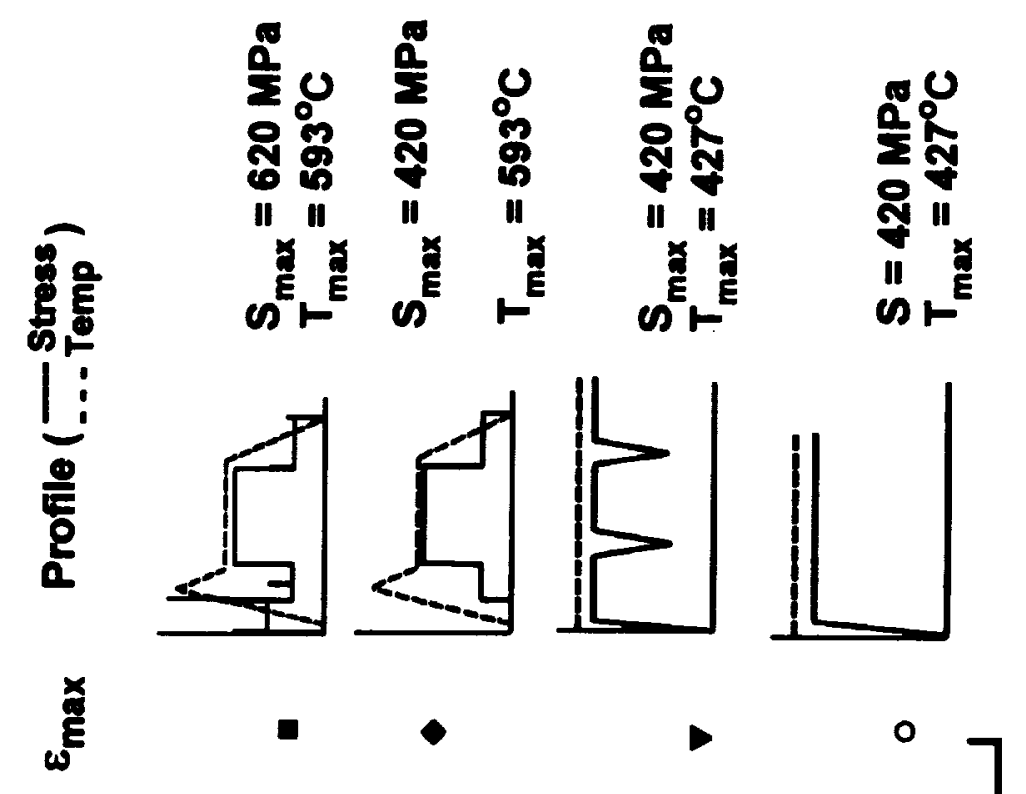

8
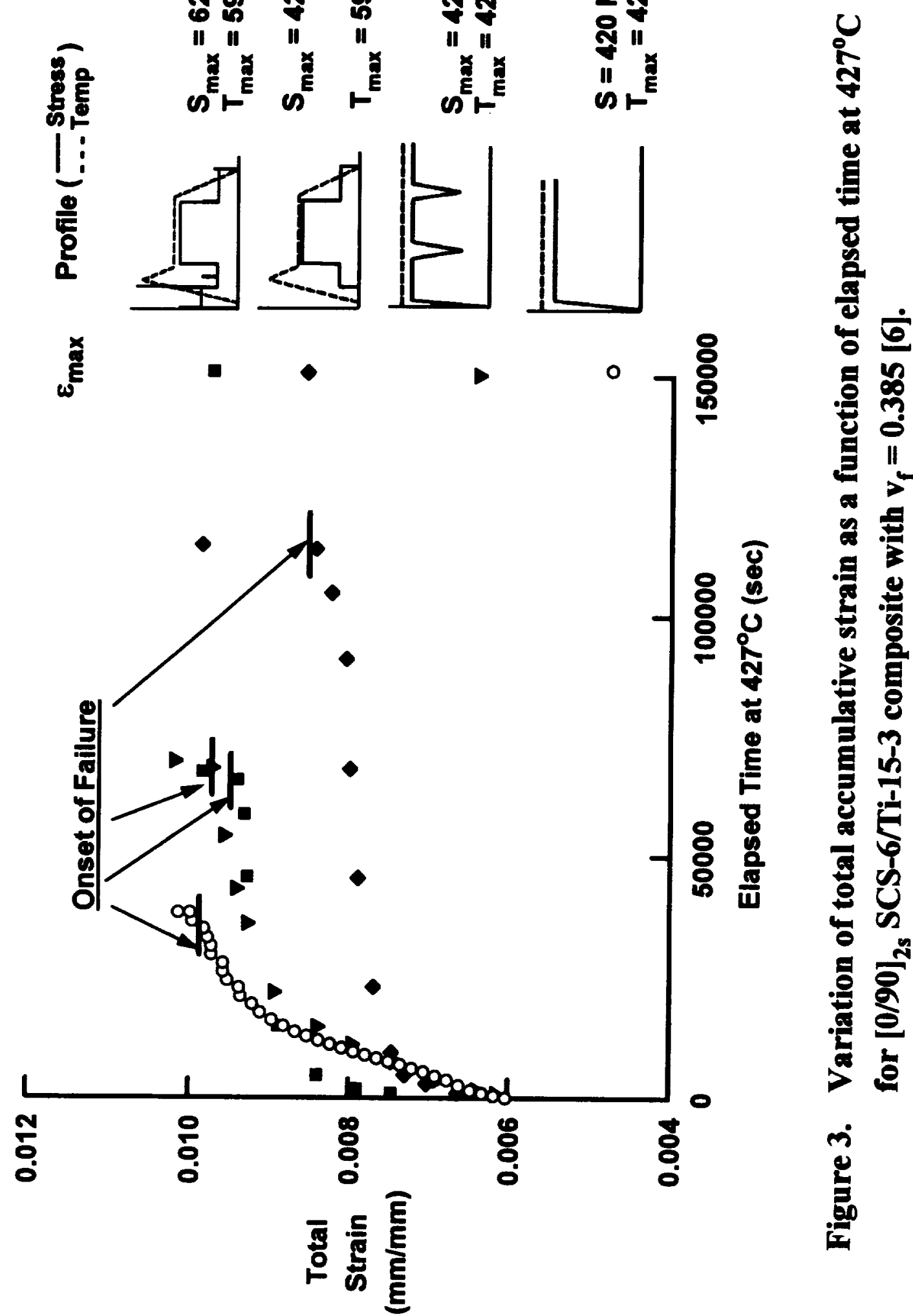

葛 

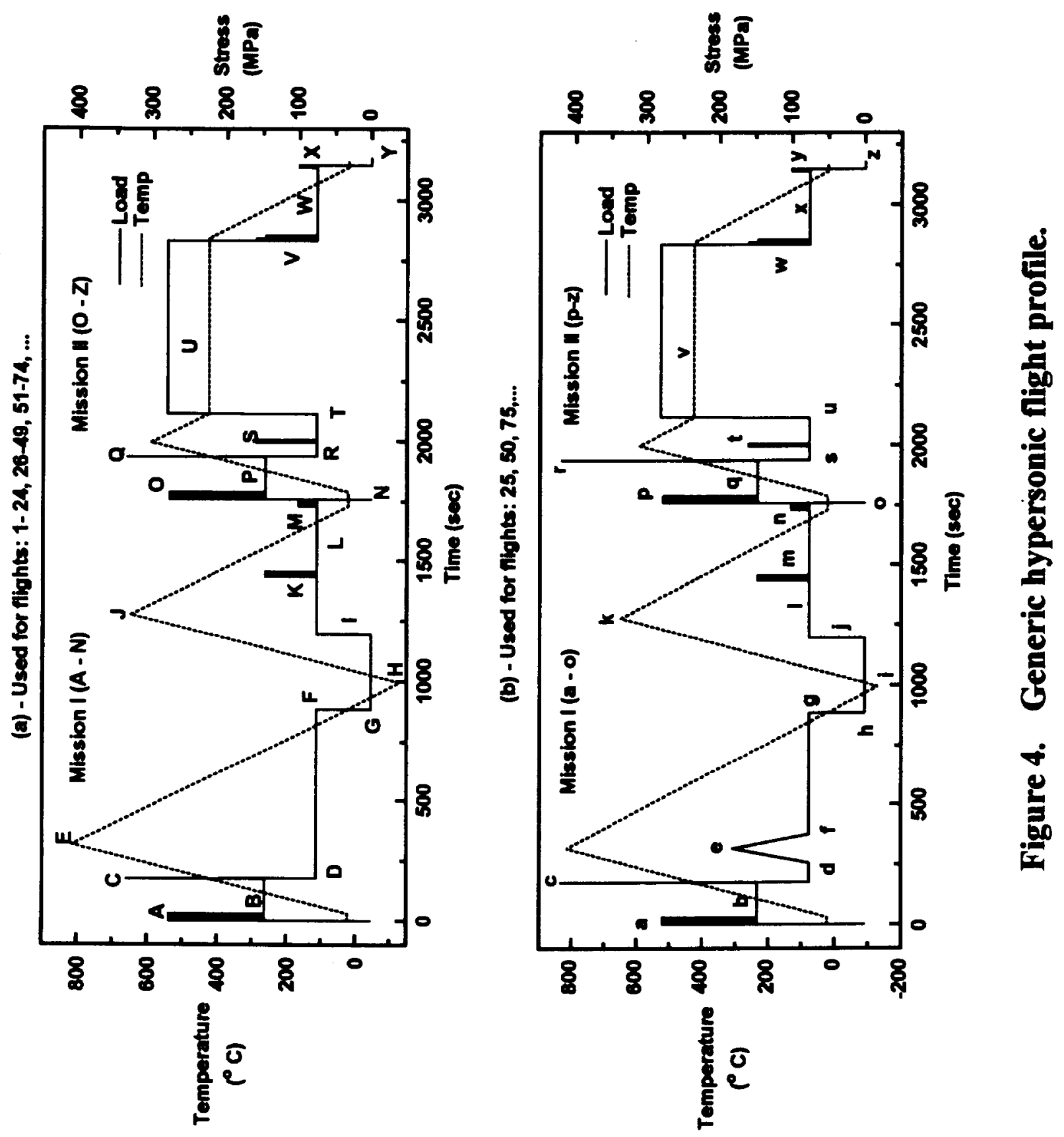


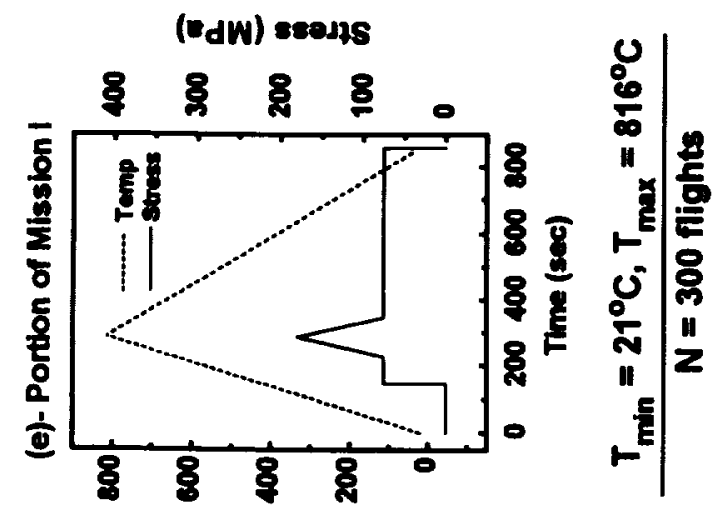

(D) dwol

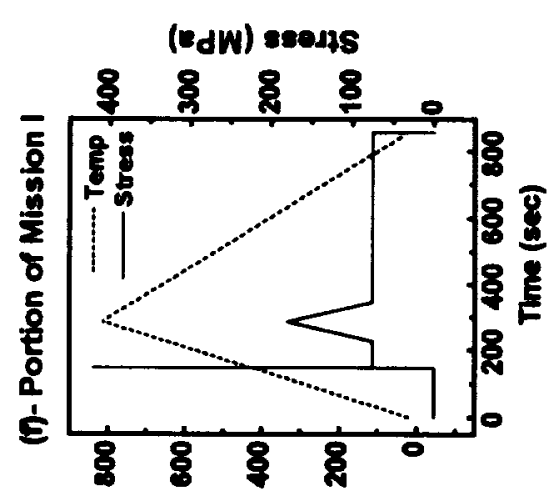

(O) dwol

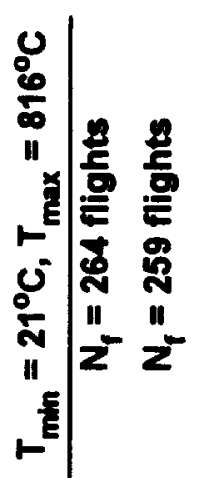

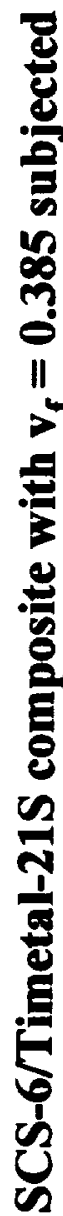

(EdW) seajs

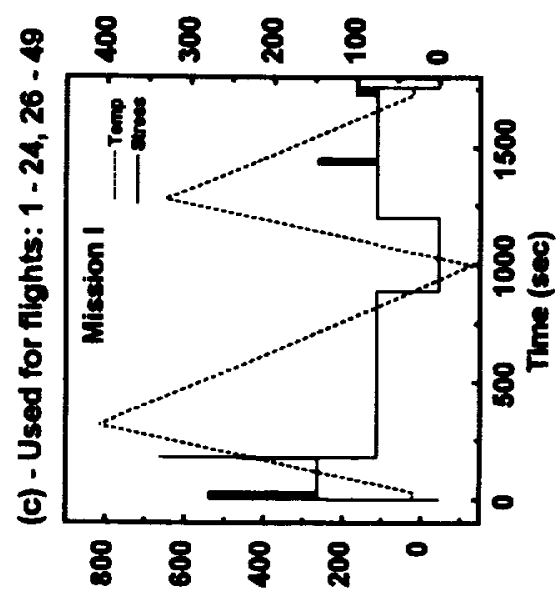

(2) dwol
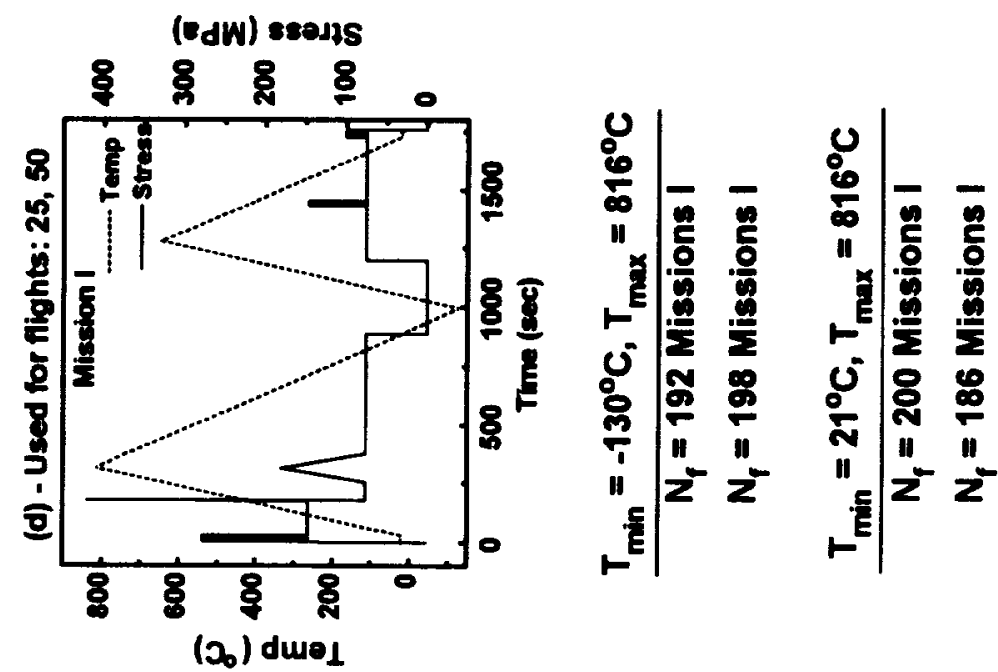

(2) dwe 1
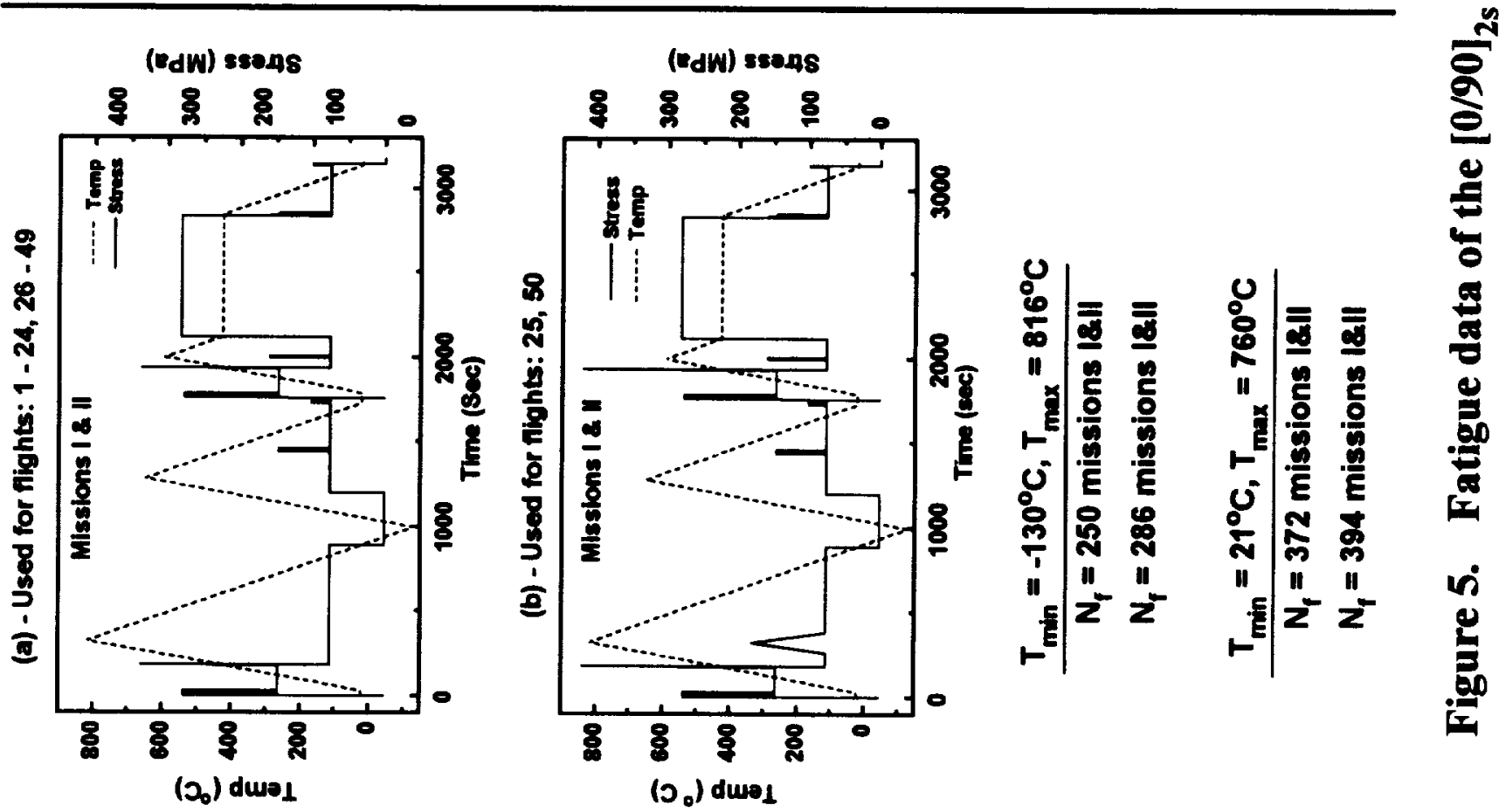
y .ํㅡㄹ 


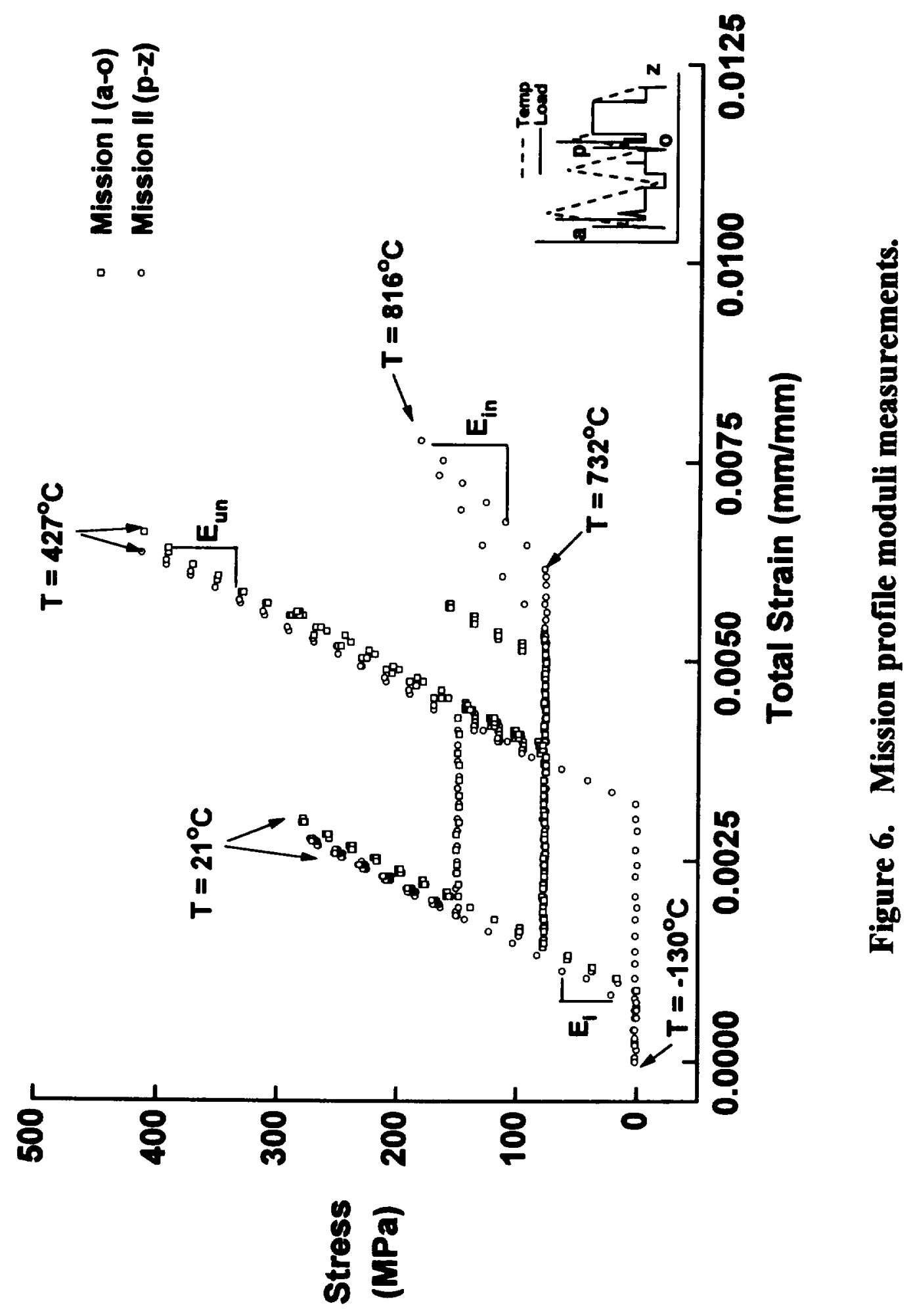



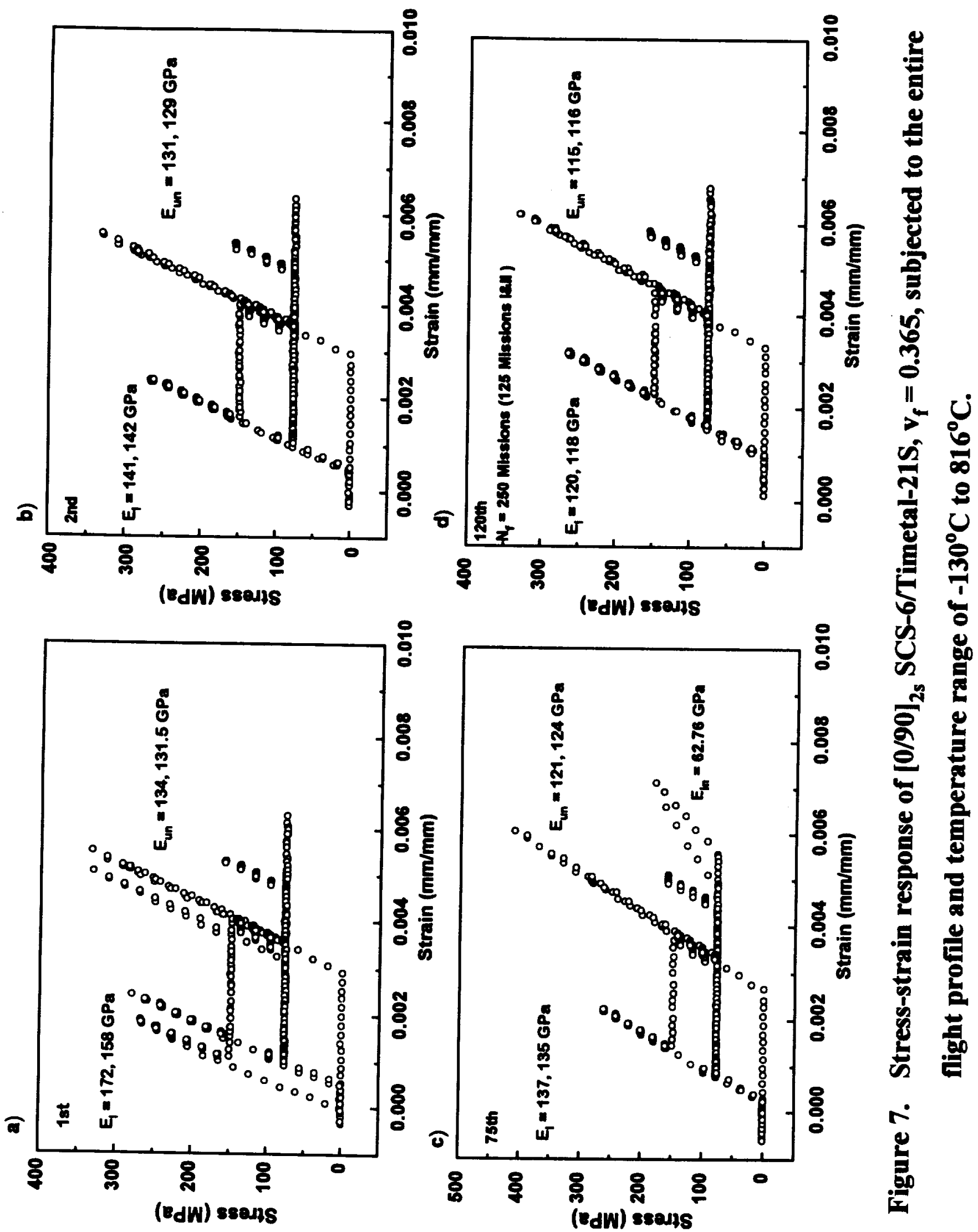


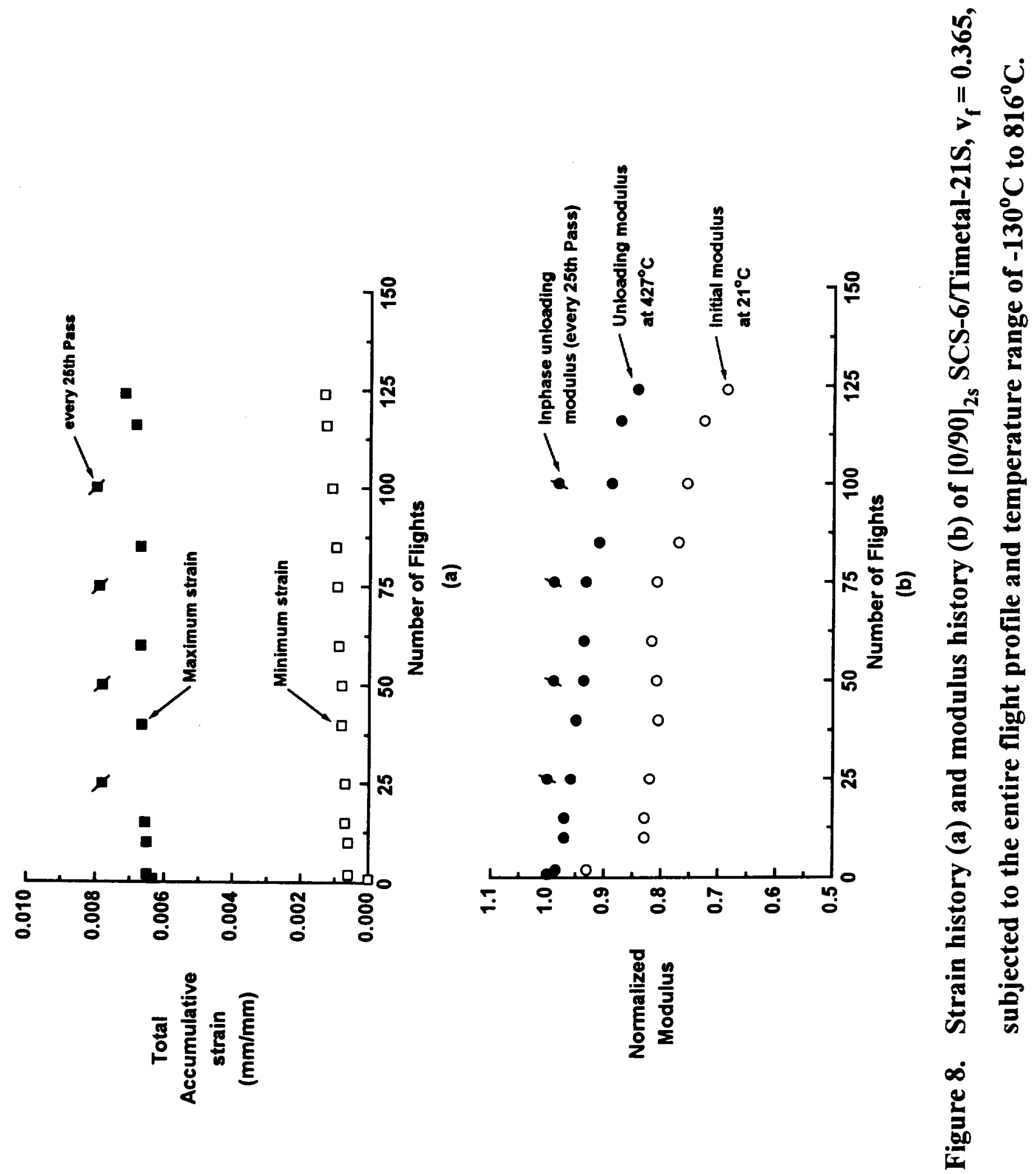



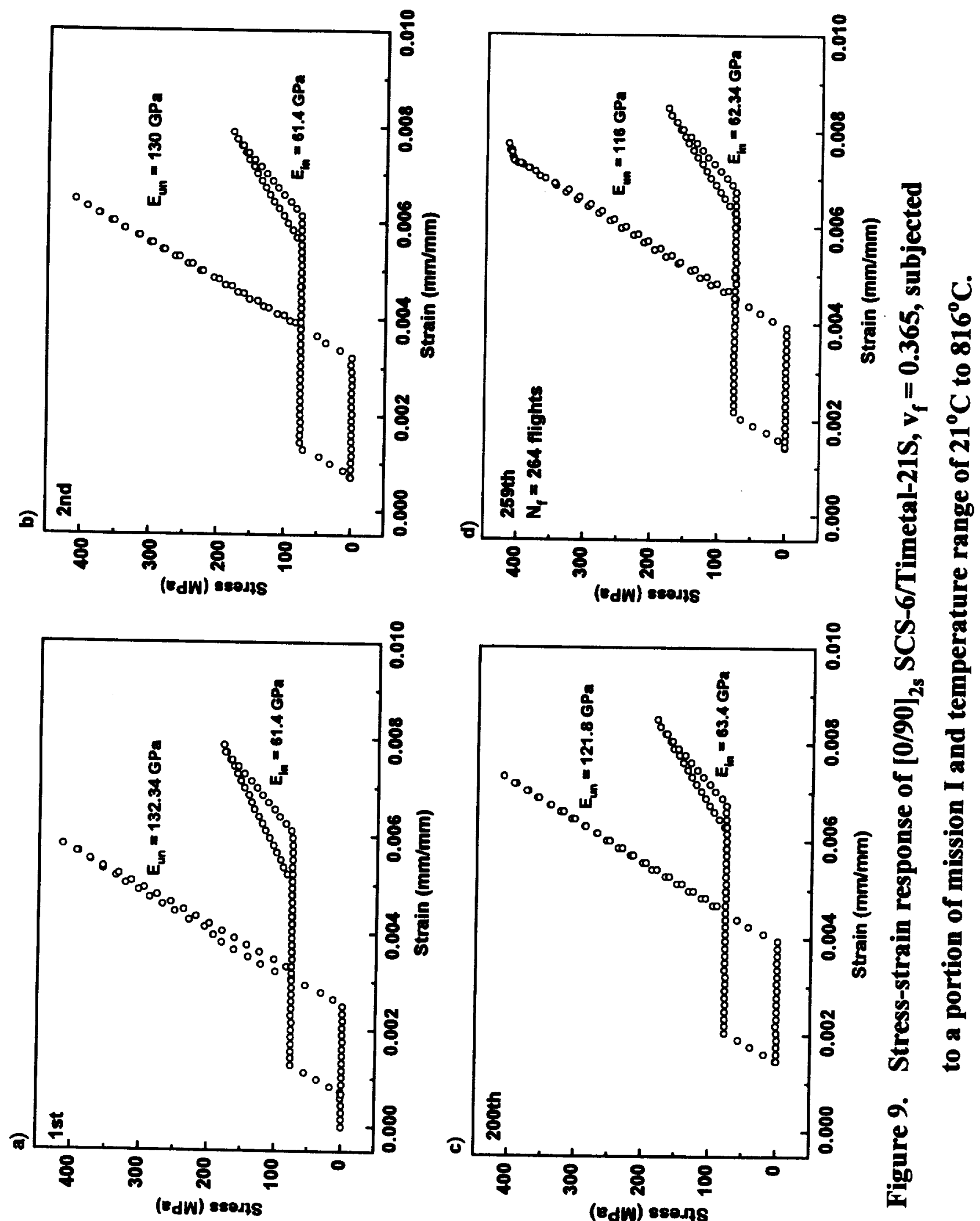


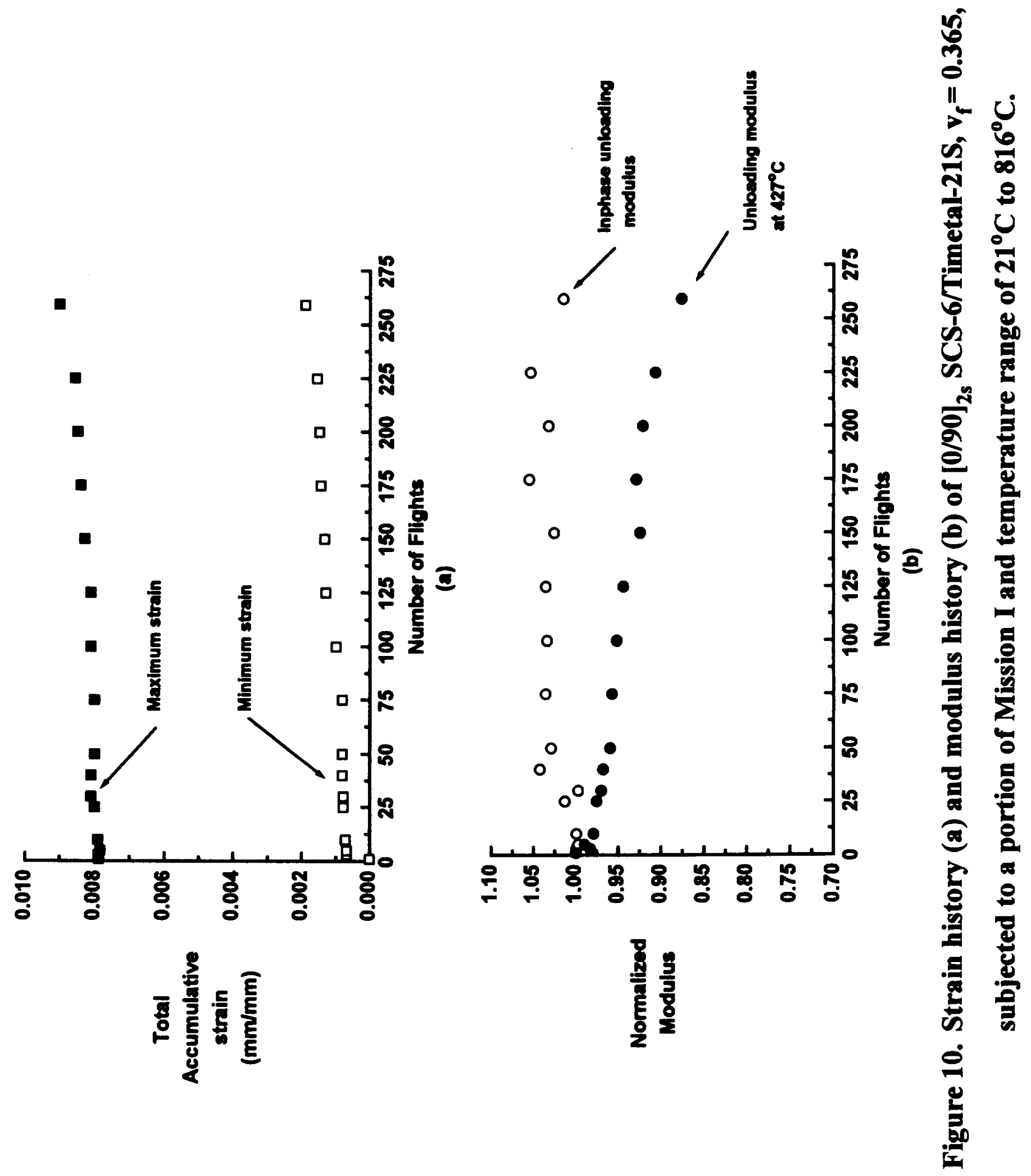




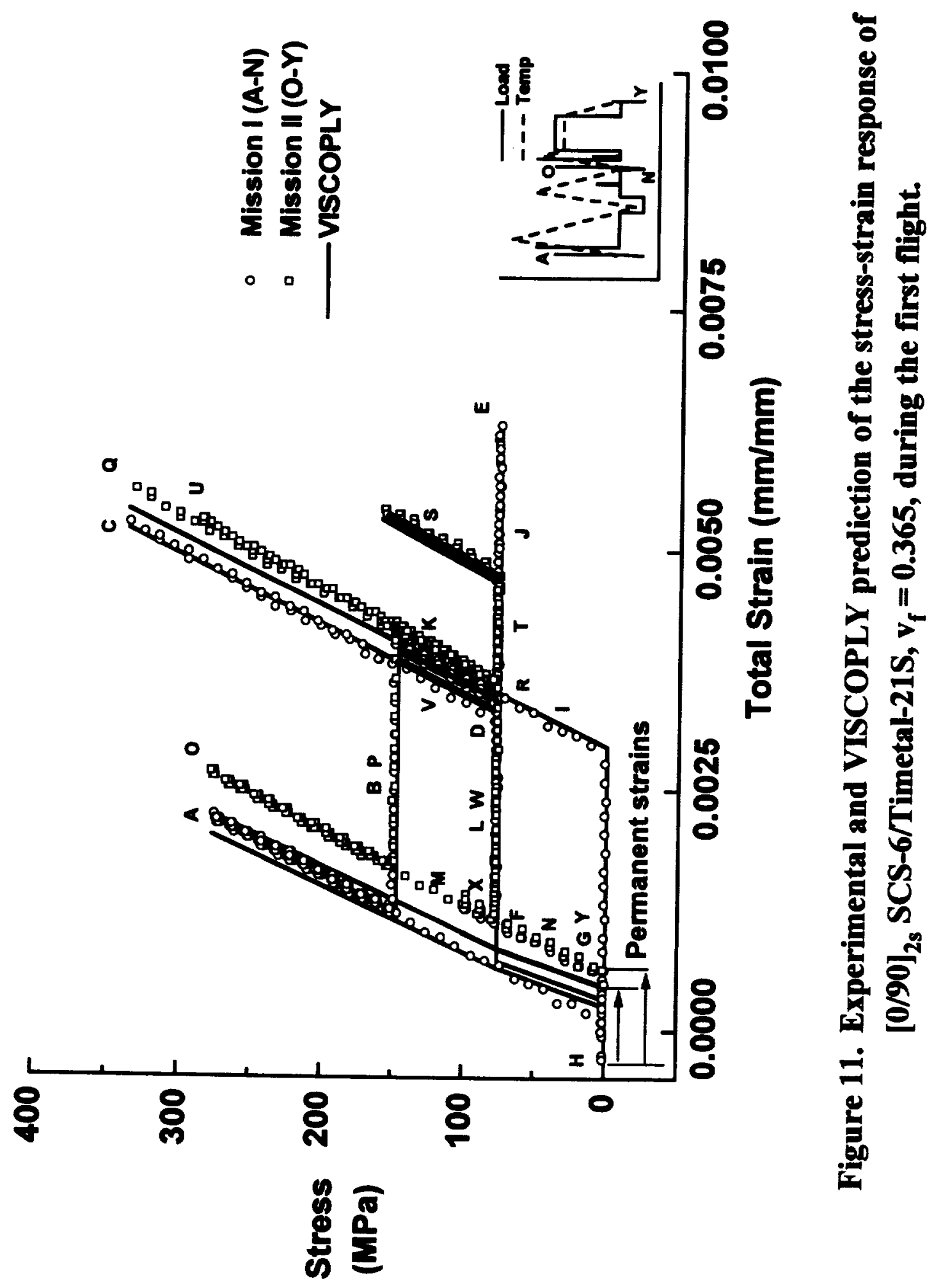




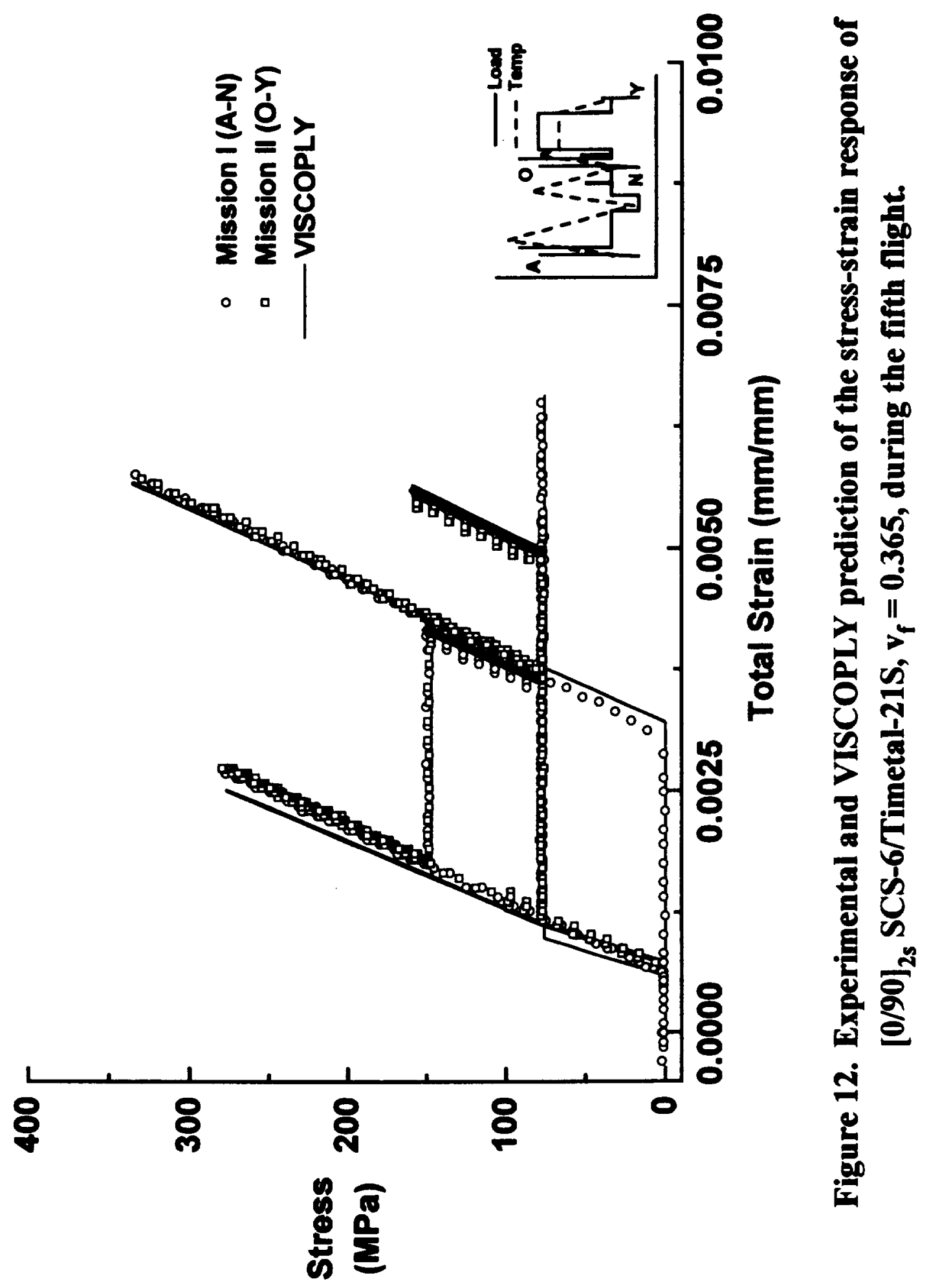




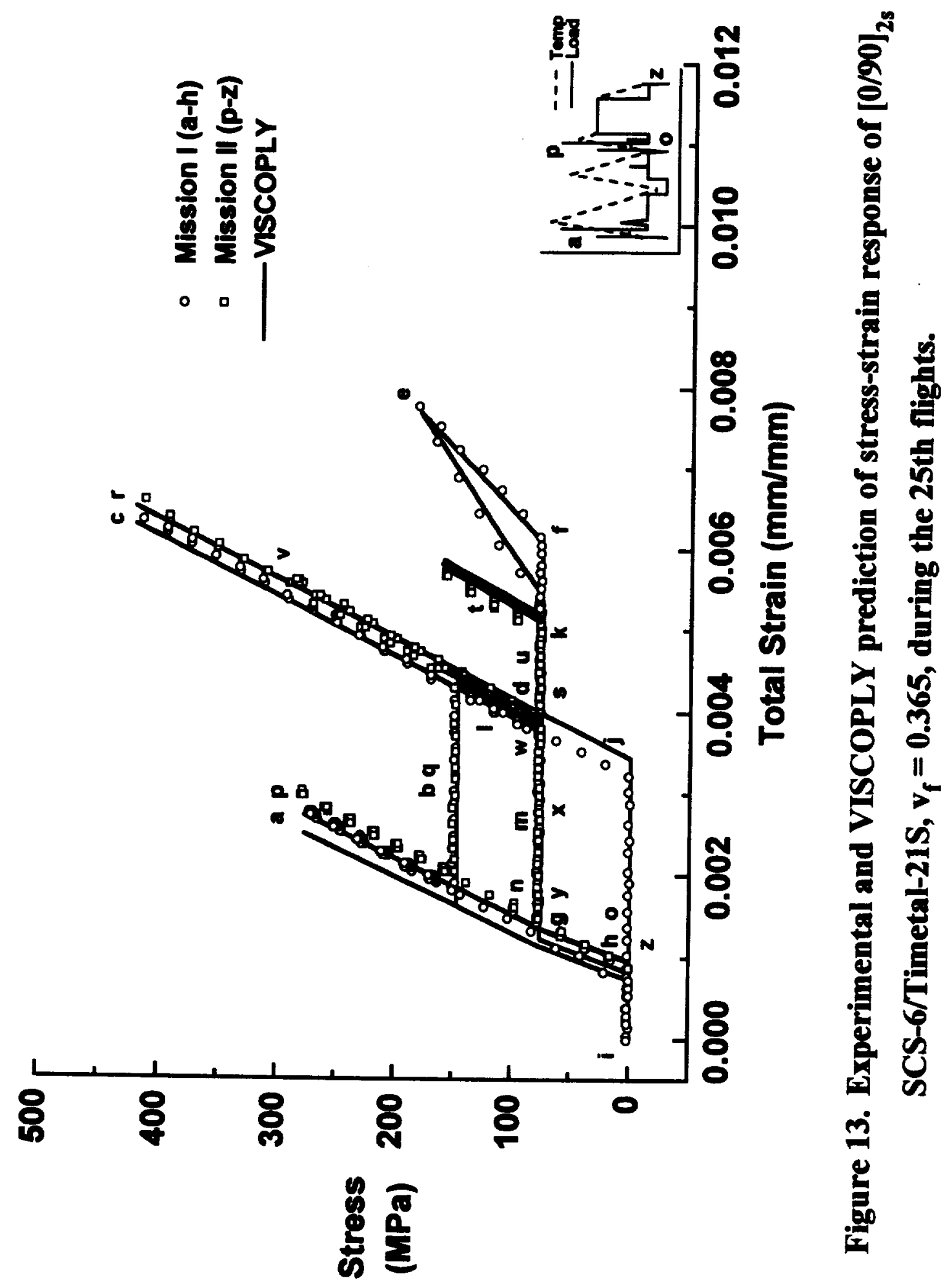




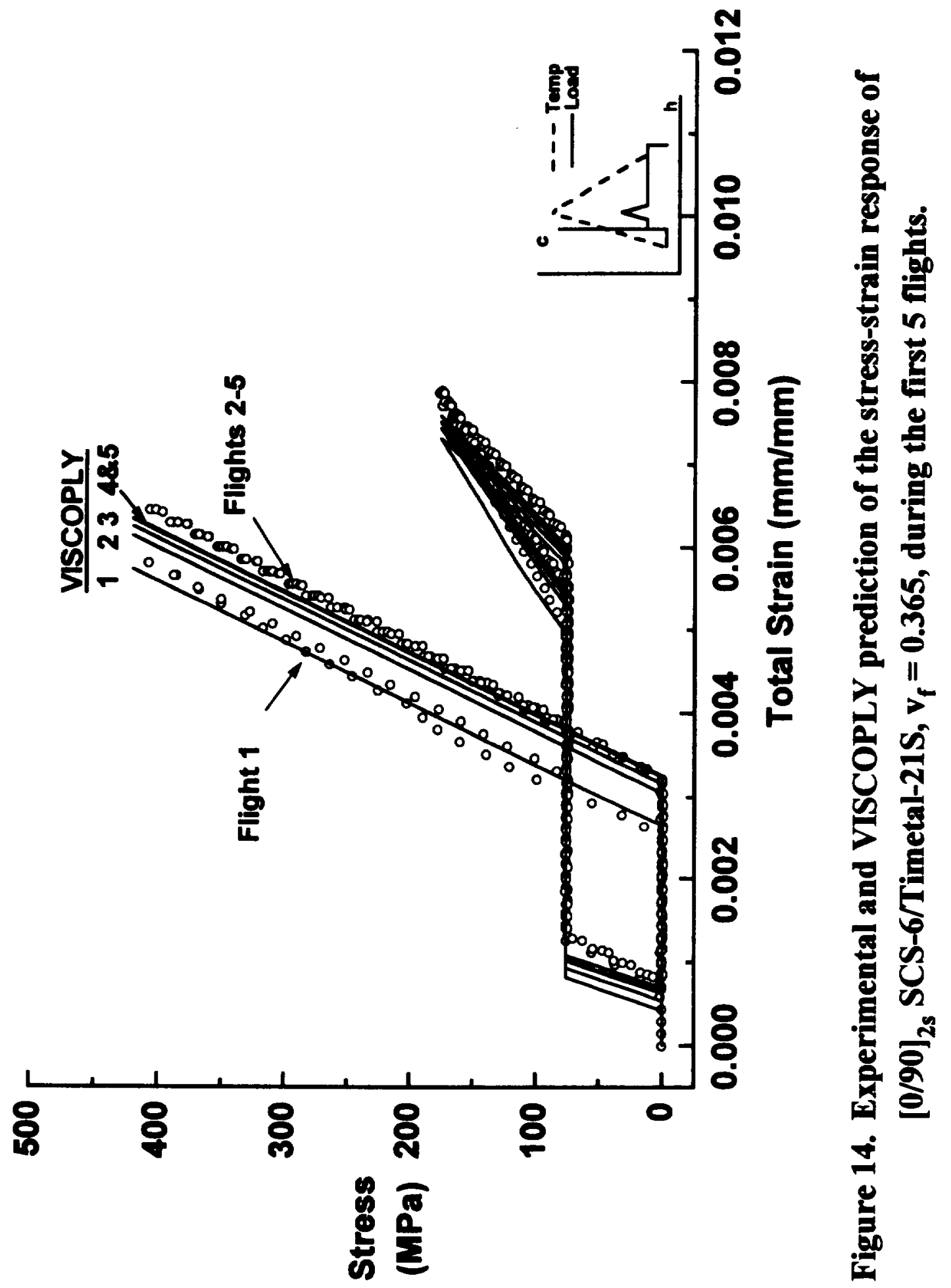



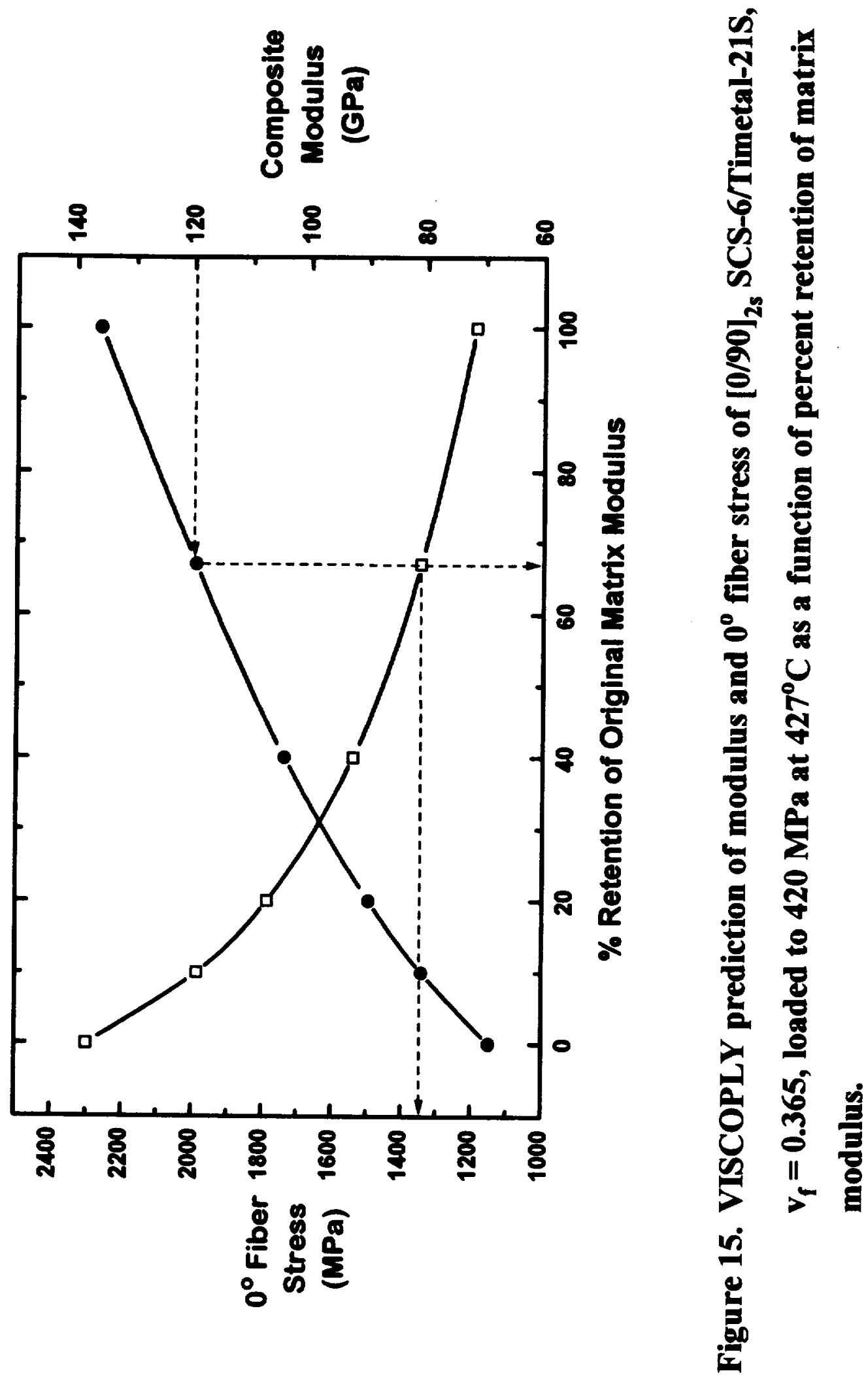


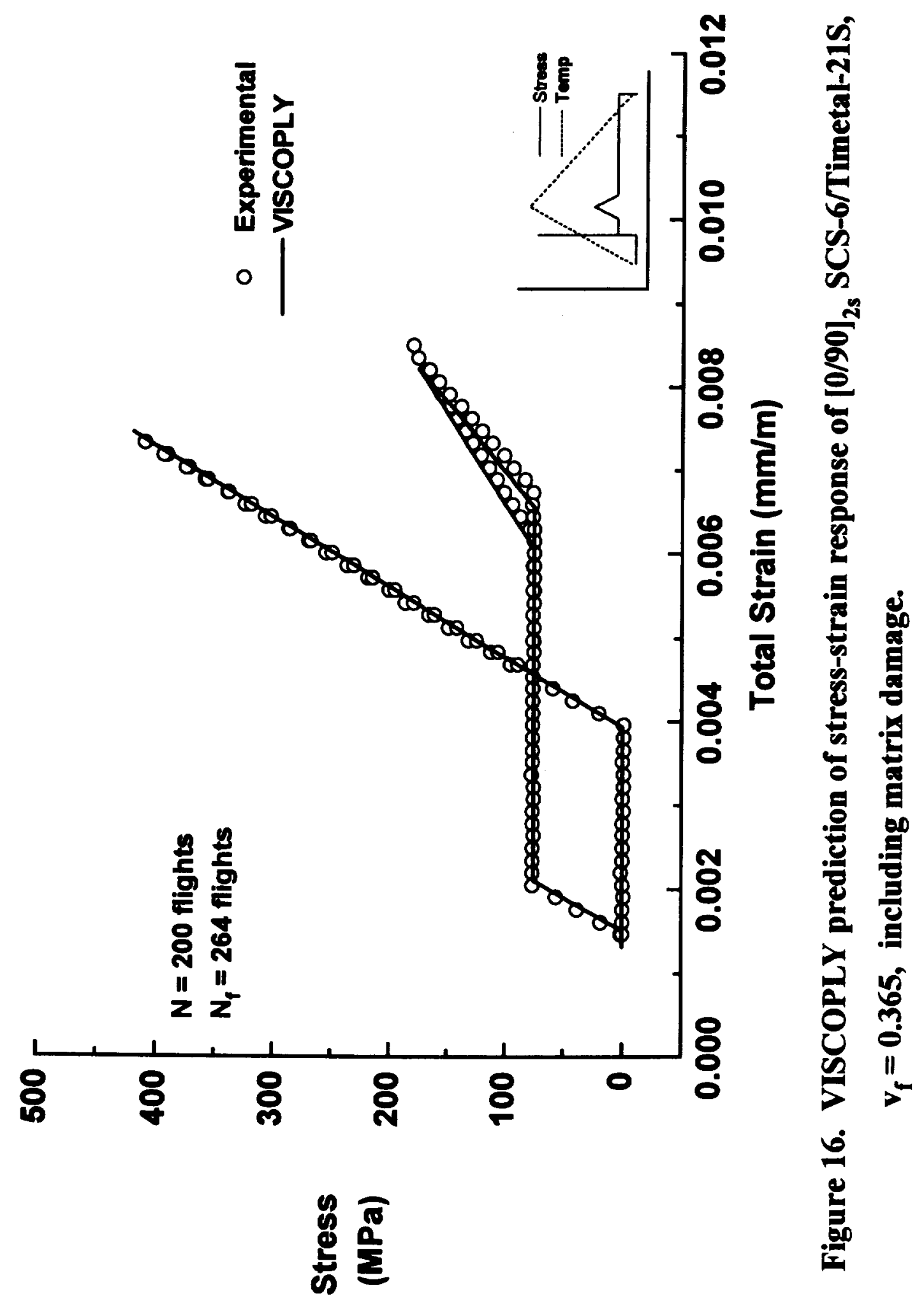




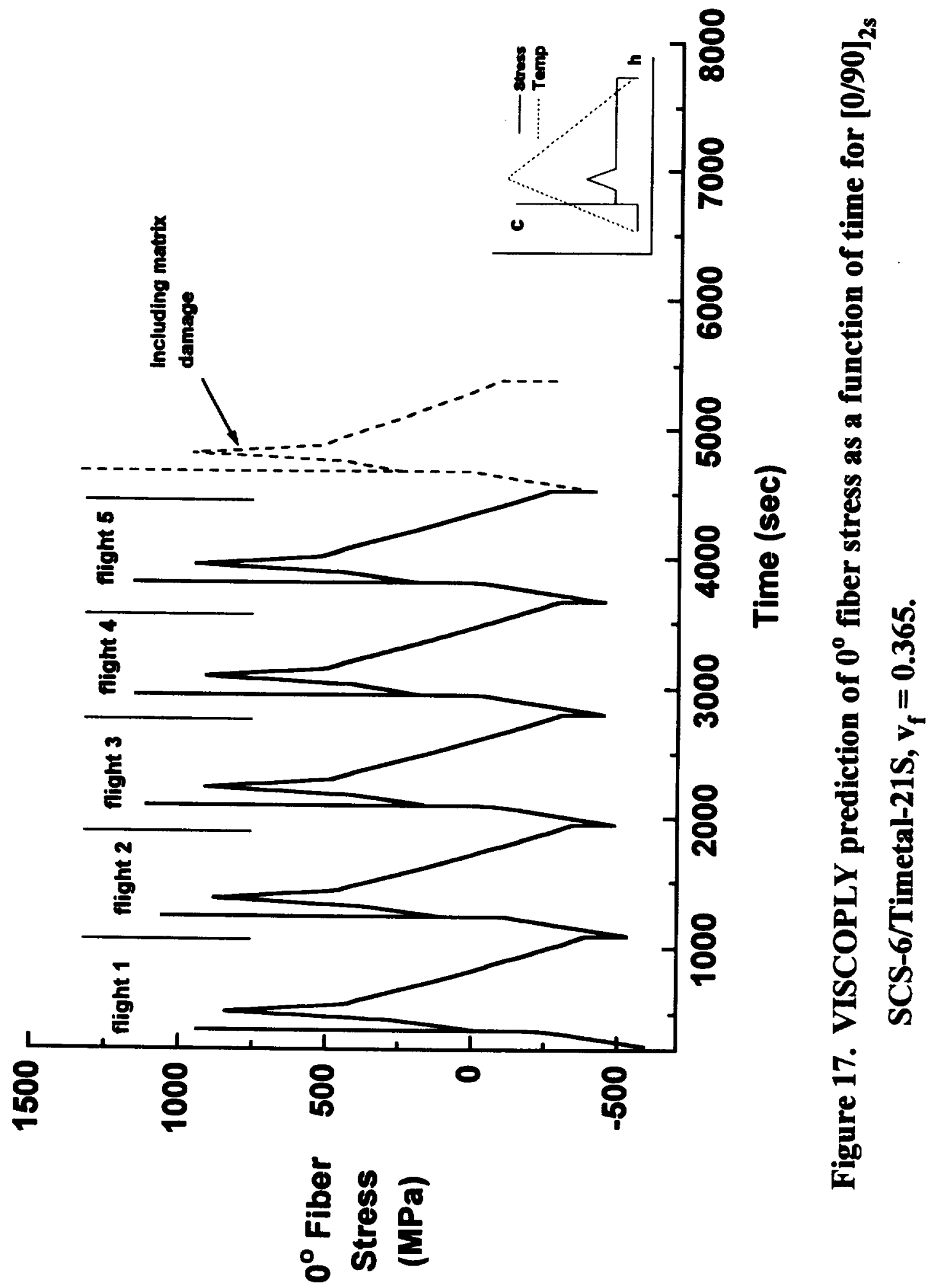




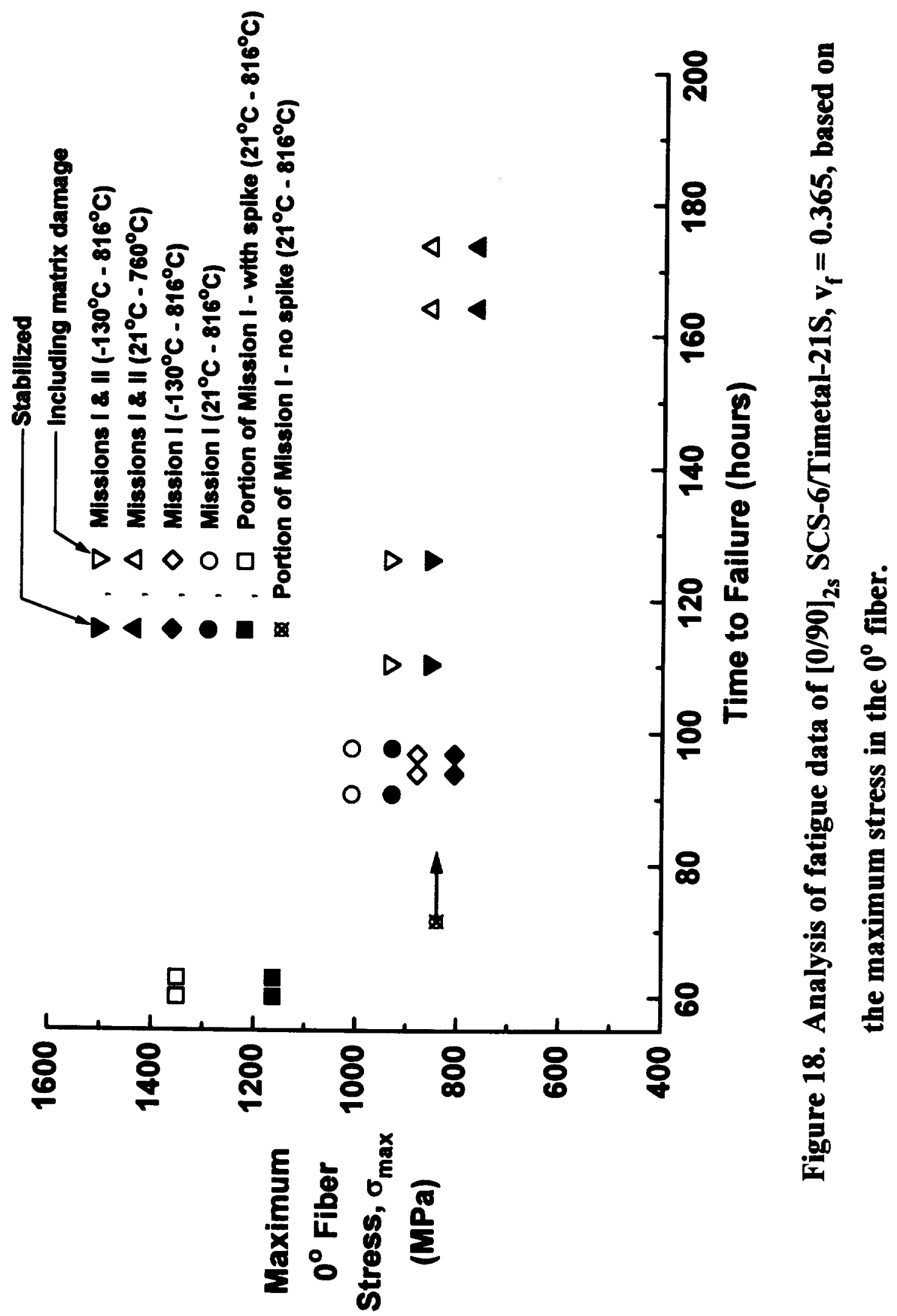




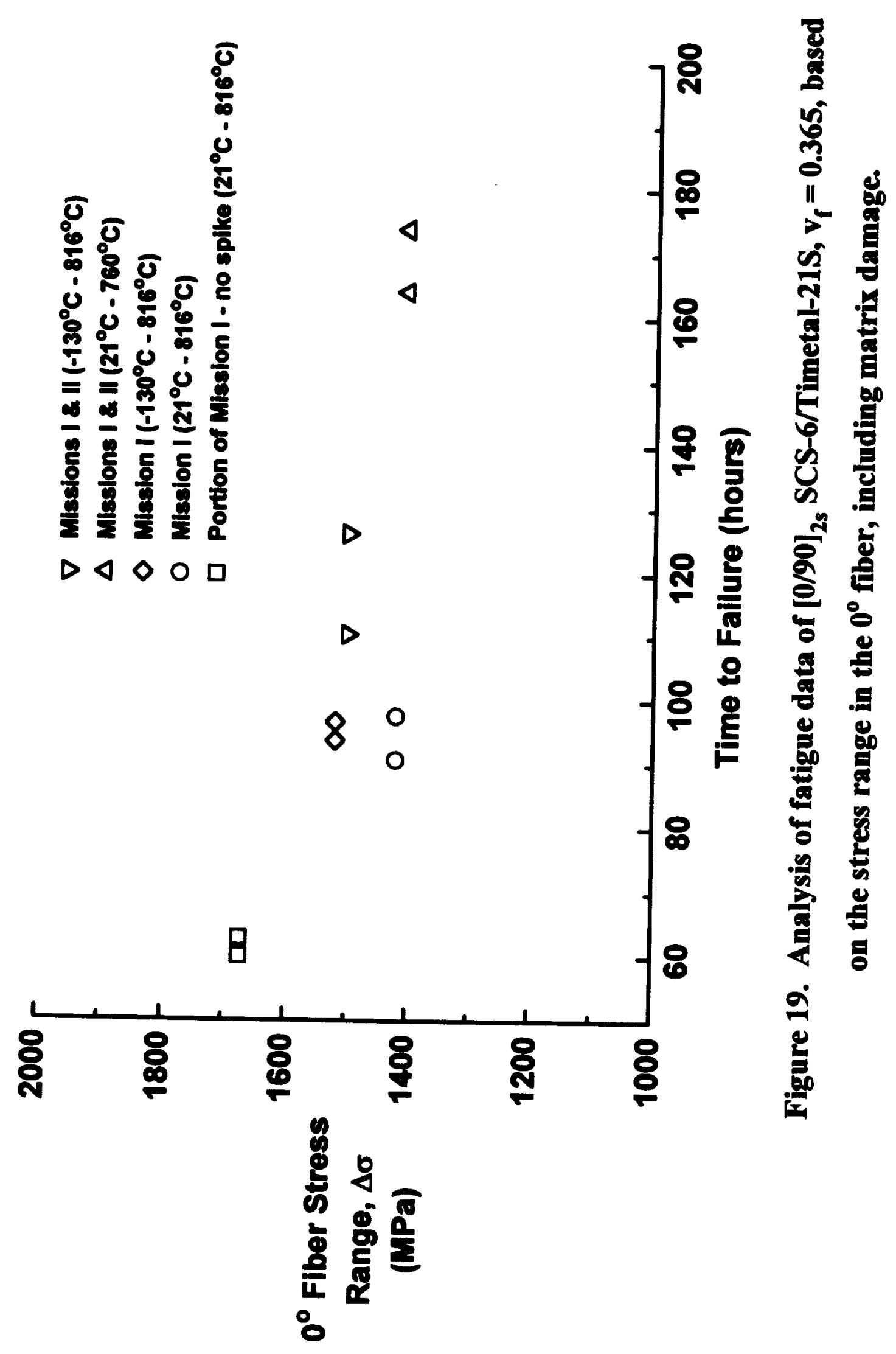




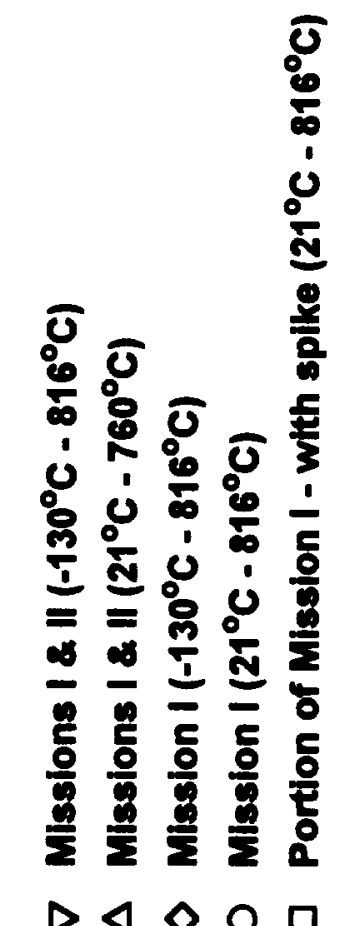

$\frac{9}{8}$

焉

i

\%

$=\equiv$

- $4 \frac{1}{1}$

$\div= \pm$

흥흐응 홍 을

$\triangleright \triangleleft \diamond 0$

$\triangleleft$

$\triangleleft$
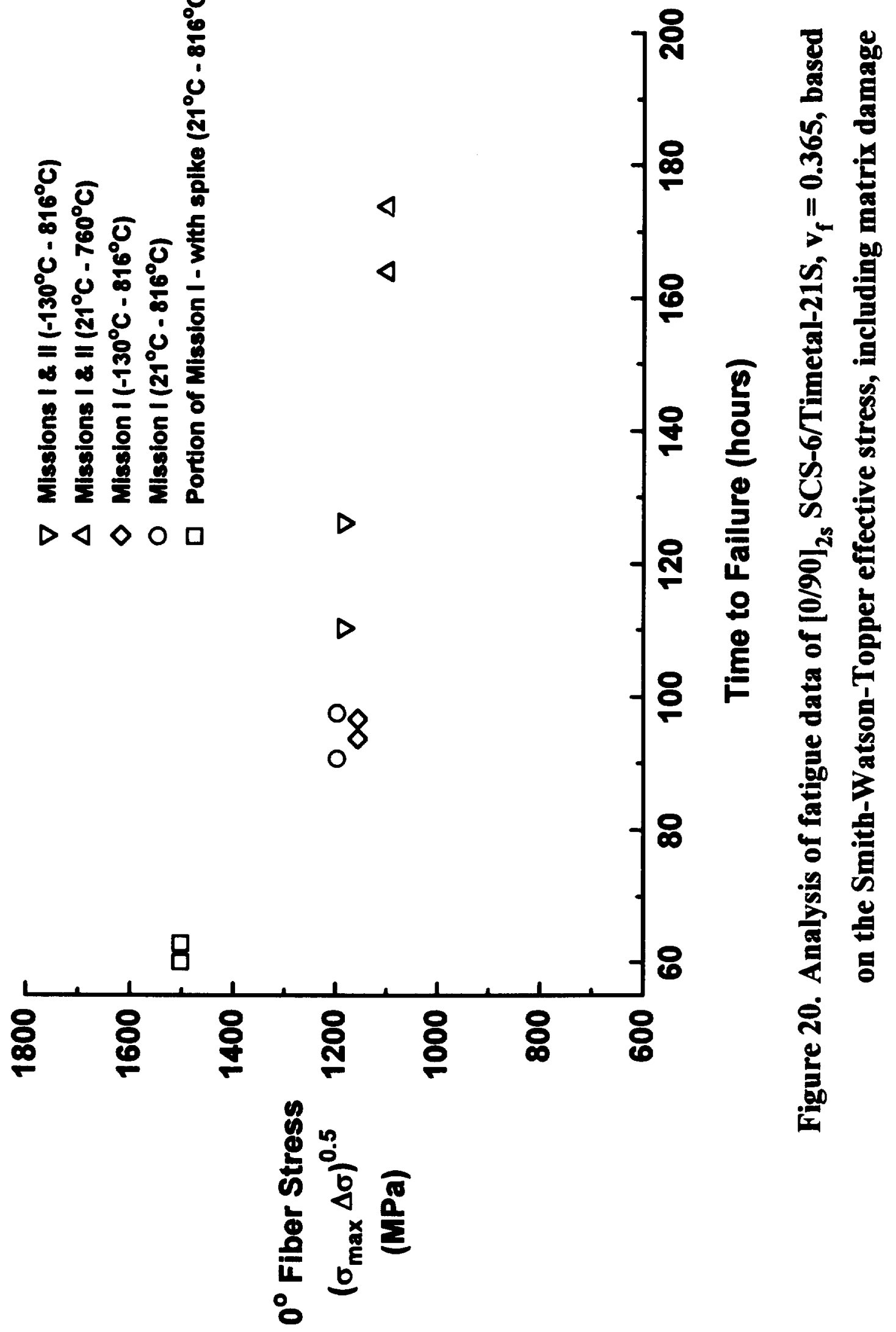


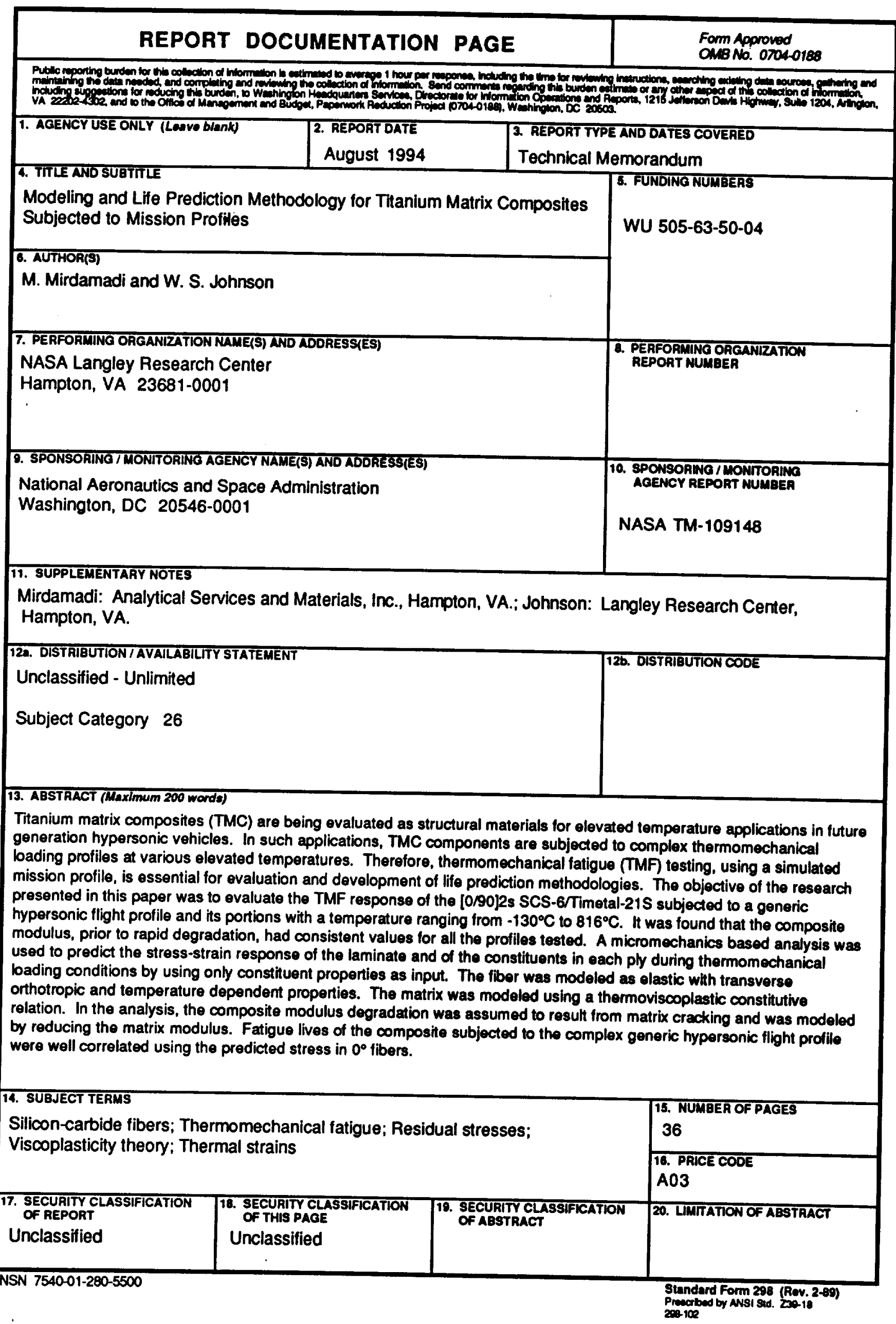

